\title{
BMJ Open Work of being an adult patient with chronic kidney disease: a systematic review of qualitative studies
}

\author{
Javier Roberti, ${ }^{1}$ Amanda Cummings, ${ }^{2,3}$ Michelle Myall, ${ }^{2,3}$ Jonathan Harvey, ${ }^{2}$ \\ Kate Lippiett, ${ }^{2}$ Katherine Hunt, ${ }^{2}$ Federico Cicora, ${ }^{1}$ Juan Pedro Alonso, ${ }^{4}$ Carl R May ${ }^{5}$
}

To cite: Roberti J, Cummings A, Myall $\mathrm{M}$, et al. Work of being an adult patient with chronic kidney disease: a systematic review of qualitative studies. BMJ Open 2018;8:e023507. doi:10.1136/ bmjopen-2018-023507

- Prepublication history and additional material for this paper are available online. To view these files, please visit the journal online (http://dx.doi org/10.1136/bmjopen-2018023507).

Received 9 April 2018 Revised 28 June 2018 Accepted 8 August 2018

Check for updates

(c) Author(s) (or their employer(s)) 2018. Re-use permitted under CC BY-NC. No commercial re-use. See rights and permissions. Published by BMJ.

${ }^{1}$ FINAER, Foundation for Research and Assistance of Kidney Disease, Buenos Aires, Argentina

${ }^{2}$ Faculty of Health Sciences, University of Southampton,

Southampton, UK

${ }^{3}$ NIHR CLAHRC Wessex, University of Southampton,

Southampton, UK

${ }^{4}$ Faculty of Social Sciences, Universidad de Buenos Aires, Buenos Aires, Argentina

${ }^{5}$ London School of Hygiene and Tropical Medicine, Faculty of Epidemiology and Population Health, London, UK

Correspondence to Javier Roberti; javierroberti@gmail.com

\section{ABSTRACT}

Introduction Chronic kidney disease (CKD) requires patients and caregivers to invest in self-care and selfmanagement of their disease. We aimed to describe the work for adult patients that follows from these investments and develop an understanding of burden of treatment (BoT).

Methods Systematic review of qualitative primary studies that builds on EXPERTS1 Protocol, PROSPERO registration number: CRD42014014547. We included research published in English, Spanish and Portuguese, from 2000 to present, describing experience of illness and healthcare of people with CKD and caregivers. Searches were conducted in MEDLINE, Embase, CINAHL Plus, PsycINF0, Scopus, Scientific Electronic Library Online and Red de Revistas Científicas de América Latina y el Caribe, España y Portugal. Content was analysed with theoretical framework using middle-range theories.

Results Searches resulted in 260 studies from 30 countries (5115 patients and 1071 carers). Socioeconomic status was central to the experience of CKD, especially in its advanced stages when renal replacement treatment is necessary. Unfunded healthcare was fragmented and of indeterminate duration, with patients often depending on emergency care. Treatment could lead to unemployment, and in turn, to uninsurance or underinsurance. Patients feared catastrophic events because of diminished financial capacity and made strenuous efforts to prevent them. Transportation to and from haemodialysis centre, with variable availability and cost, was a common problem, aggravated for patients in non-urban areas, or with young children, and low resources. Additional work for those uninsured or underinsured included fund-raising. Transplanted patients needed to manage finances and responsibilities in an uncertain context. Information on the disease, treatment options and immunosuppressants side effects was a widespread problem.

Conclusions Being a person with end-stage kidney disease always implied high burden, time-consuming, invasive and exhausting tasks, impacting on all aspects of patients' and caregivers' lives. Further research on BoT could inform healthcare professionals and policy makers about factors that shape patients' trajectories and contribute towards a better illness experience for those living with CKD.

PROSPERO registration number CRD42014014547.

\section{Strengths and limitations of this study}

- We analysed data with a coding framework supported by middle-range theories to understand the work involved in being a person with chronic kidney disease.

- Comprehensive inclusion of publications in English, Spanish and Portuguese, which may enhance the transferability of our findings.

- The variety of methodologies, quality of reporting and heterogeneity of perspectives make synthesis difficult.

\section{INTRODUCTION}

Chronic kidney disease (CKD) contributes significantly to global morbidity and mortality. ${ }^{1-4}$ Even in its early stages, the risk of death, cardiovascular events, cerebrovascular disorders, hospitalisation, reduced health-related quality of life, anxiety, depression and suicidal ideation is increased. ${ }^{1-6}$

Worldwide, about 500 million people are affected by CKD; about $80 \%$ of these live in low-income and middle-income countries (LMIC); an estimated 3 million people with end-stage kidney disease (ESKD) receive renal replacement therapy (RRT) with either dialysis or transplantation. ${ }^{178}$ The number of people receiving RRT is increasing and will more than double by 2030, but a significant number of people without access to this type of live-saving treatment will remain. ${ }^{9}$ In 2010 , at least 2.28 million people might have died because of lack of access to RRT, mostly in LMIC in Asia, Africa and Latin America. ${ }^{9}$

Much is now known about the pathophysiological and treatment trajectories of CKD, and about the associated burden of symptoms experienced by patients. More recently, there has been increasing interest in the way that complex long-term conditions require patients and their carers to invest in self-care and self-management of their disease. ${ }^{10-15}$ The work for patients and carers that follows 
from these investments, including medication management, medical visits, laboratory tests, lifestyle changes and monitoring in addition to the activities done as part of life, is here termed burden of treatment (BoT), which adds to the burden of symptoms (BoS). ${ }^{101316}$ Research on BoT has focused on long-term conditions such as diabetes, chronic obstructive pulmonary disease and chronic heart failure, with the development of analytic framework and patient-created taxonomies. ${ }^{10-27}$ Patients and carers are expected to actively participate in managing both index conditions and comorbidities and, depending on their resources or lack thereof, they often need to negotiate or renegotiate the responsibilities that healthcare providers and healthcare systems assign to them. ${ }^{13} 2829$ Patients' and carers' experience in managing the disease and its treatment, including their choices and expectations, is affected by structural, relational and resilience factors; the interactions among these factors remain understudied. ${ }^{30}$ The aim of this study is to develop specific understanding of treatment burden experienced by people with CKD and ESKD extending it to experiences of uninsured and underinsured patients in LMIC.

\section{METHODS}

This is a systematic review of primary qualitative studies, which builds on the published EXPERTS1 Protocol and its meta-review of qualitative reviews. ${ }^{30} 31$ PROSPERO registration number is CRD42014014547. This review follows the Enhancing Transparency in Reporting the Synthesis of Qualitative Research framework. ${ }^{32}$ We interrogated a subset of qualitative primary research papers concerned with CKD identified by EXPERTS1 qualitative meta-review to understand the dynamics of patient experience of complexity and treatment burden in long-term life-limiting conditions. EXPERTS1 search was updated and expanded to Spanish and Portuguese language literature.

\section{Eligibility, inclusion and exclusion criteria}

Eligibility criteria for study inclusion were developed using the participants, interventions, comparators and

\section{Table 1 PICO criteria for including studies}

\section{Patients of at least 18 years of age,} diagnosed with CKD, and formal and

Population informal carers.

\begin{tabular}{ll}
\hline Intervention & $\begin{array}{l}\text { Experiences of healthcare provision, any } \\
\text { type of treatment for CKD. }\end{array}$ \\
Comparator & Not limited to comparator studies. \\
Outcomes & $\begin{array}{l}\text { Qualitative data on patients' and carers' } \\
\text { experiences of care for those patients with } \\
\text { CKD. }\end{array}$ \\
Study type & $\begin{array}{l}\text { Primary studies, qualitative or mixed } \\
\text { methods studies. }\end{array}$ \\
Time & From 2000 to present.
\end{tabular}

CKD, chronic kidney disease; PICO, participants, interventions, comparators and outcomes. outcomes framework (table 1). Inclusion criteria were primary qualitative and mixed-method studies of adult patients diagnosed with CKD in any stage and their formal or informal carers; in any type of treatment or healthcare provision; not limited to comparative studies; with qualitative data on the patients' and carers' experiences on any aspect of CKD, in any stage, and its treatments; in English, Spanish and Portuguese. Following the EXPERTS1 protocol, studies were excluded if they were of other EXPERTS1 index conditions; if they reported results of treatments, interventions, tests or surveys; were guidelines, discussions of the literature or editorials, notes, news, letters and case reports; if the experiences described by patients and carers could not be clearly discriminated. ${ }^{31}$ Studies describing experiences of children with CKD were excluded because their BoT may be significantly different from that of adult patients. The year of publication 2000 onwards was established to include current treatments.

\section{Study selection}

A first search for the EXPERTS1 meta-review was conducted in MEDLINE, Embase, CINAHL Plus, PsycINFO and Scopus. For this review, searches were updated using the same databases and expanded to include studies published in Spanish and Portuguese with additional searches in the Iberoamerican databases Scientific Electronic Library Online and Red de Revistas Científicas de América Latina y el Caribe, España y Portugal. Searches were completed by April 2017 and identified papers published between 1 January 2000 and March 2017. Search strategy is included in supplementary appendix 1 . For a first set of studies, titles and abstracts were independently screened by AC, MM and CRM, disagreements resolved by JH. Full-text papers $(\mathrm{n}=1238)$ were obtained and screened by JH, KAL and MM; disagreements resolved by KH or AC. Of 606 articles, 191 were related to CKD. For a second set, updated results in English and studies in Spanish and Portuguese were screened by JR, JPA, disagreements resolved by FC. Two authors (JR, JPA) assessed papers against the Critical Appraisal Skills Programme qualitative research checklist. ${ }^{33}$ As there is no accepted criteria for the exclusion of qualitative studies-based appraisal score, we did not exclude studies based on quality. See figure 1 for screening and selection process.

\section{Data extraction and analysis}

Data outlining study characteristics are shown in table 2. Manuscripts were entered into Atlas.Ti V.7.5.12 (Scientific Software Development $\mathrm{GmbH}$ ). The results sections and participant quotations of the primary studies were analysed line-by-line using directed content analysis, sometimes called framework analysis. ${ }^{34}$ The coding frame drew on concepts from the Burden of Treatment Theory and the Cognitive Authority Theory. ${ }^{18-21} 293536$ Coding was conducted by JR and CRM, with a third party involved for disagreements (JPA), and reviewed and discussed by 


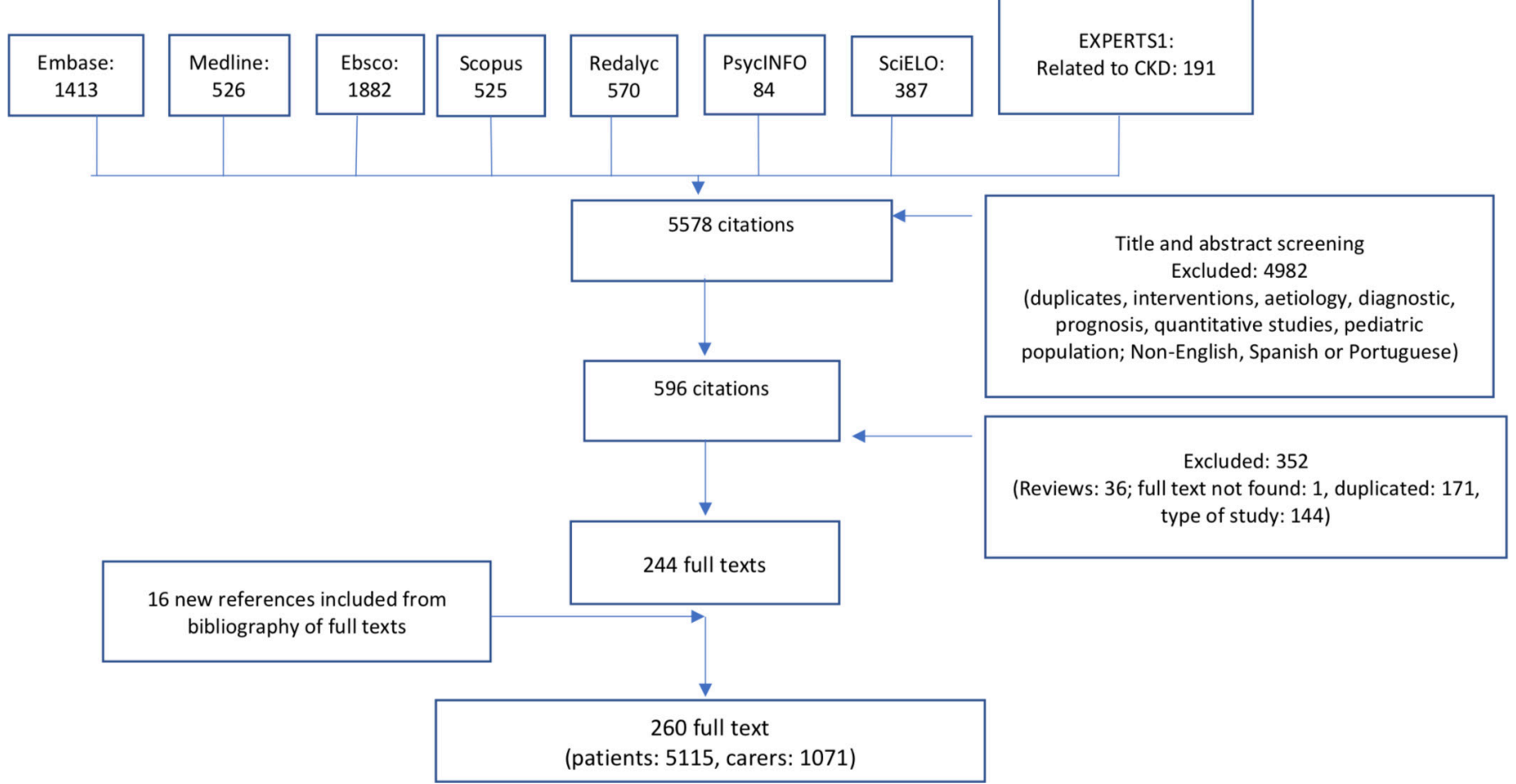

Figure 1 Preferred Reporting Items for Systematic Reviews and Meta-Analyses flow chart of screening and selection process. CKD, chronic kidney disease.

two researchers (AC, MM). Refinement of the coding frame and analysis was iterative, codes were identified or merged reading the result sections of primary studies and consulting the theoretical framework. Investigator triangulation (comparison of results of two or more researchers) was used to capture relevant issues, reflect participants' experience as reported and ensure the credibility of the findings.

\section{Patient and public involvement}

Patients and/or public were not involved in the development of the research question. To ensure wide dissemination of this systematic review, it is published in peer-reviewed open-access journal and presented in research meetings.

\section{RESULTS}

Combined searches yielded 5407 citations and resulted in 260 studies from 30 countries included in the final analysis. A total of 5115 patients and 1071 carers were included. Countries most frequently represented in the studies were: the USA with $52(20 \%)$, the UK with 46 $(18 \%)$, Brazil with $28(11 \%)$, Australia with $25(10 \%)$, Canada with 20 (8\%), Sweden with 19 (7\%), New Zealand with $8(3 \%)$ and Iran with $7(3 \%)$ studies. Most studies $(n=193,74 \%)$ described the experiences of patients with ESKD, in dialysis or conservative treatment, $28(11 \%)$ studies reported on transplanted patients, $17(6 \%)$ studies referred to patients with CKD stages 1-4 and the remainder studies described experiences of patients with CKD in all stages. Table 2 shows characteristics of studies included in the review, box 1 shows illustrative quotations, table 3 shows summary of results and table 4 shows main challenges related to BoT.

\section{Structural inequalities}

Access to care

Poverty and other socioeconomic disadvantages such as unemployment or poor housing conditions were defining factors for lack of treatment or interrupted care. ${ }^{37-52}$ Living as a person with CKD and ESKD always implied some degree of financial burden, from having to pay for the whole dialysis treatment or transplantation surgery to out-of-pocket payments of incidentals, even in countries with universal coverage. ${ }^{35} 47-4951$ 53-63 Poorly funded or unfunded healthcare resulted in fragmented treatment across healthcare systems. ${ }^{47} 4864$ Although patients who had difficulties affording treatment were naturally more concerned with accessing healthcare than in improving services, they recognised fragmentation and lack of integration as important problems. ${ }^{40} 45-51$ Where government or private insurance coverage of ESKD treatment was limited, for example, Mexico or India, patients paid for some or all the following: vascular access, hospitalisation, medical visits, haemodialysis sessions, medication, tests, prescribed food, transport and meals. ${ }^{45} 47-506065$ In such settings, patients received dialysis treatment only if they could afford it or when they had access to free sessions. ${ }^{45}$ 47-506065 Medication was sometimes counterfeit, obtained on the black market, as legitimate medication was beyond patients' reach. ${ }^{49}$ For the uninsured, dependence on emergency care added uncertainty and 


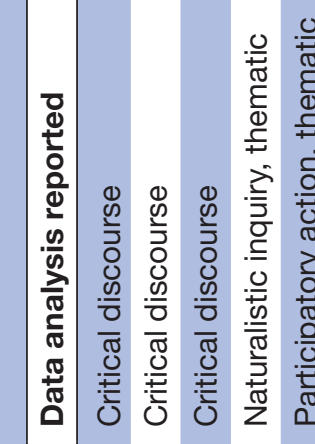

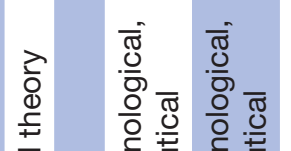

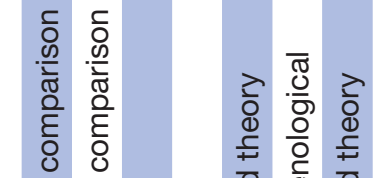

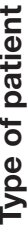
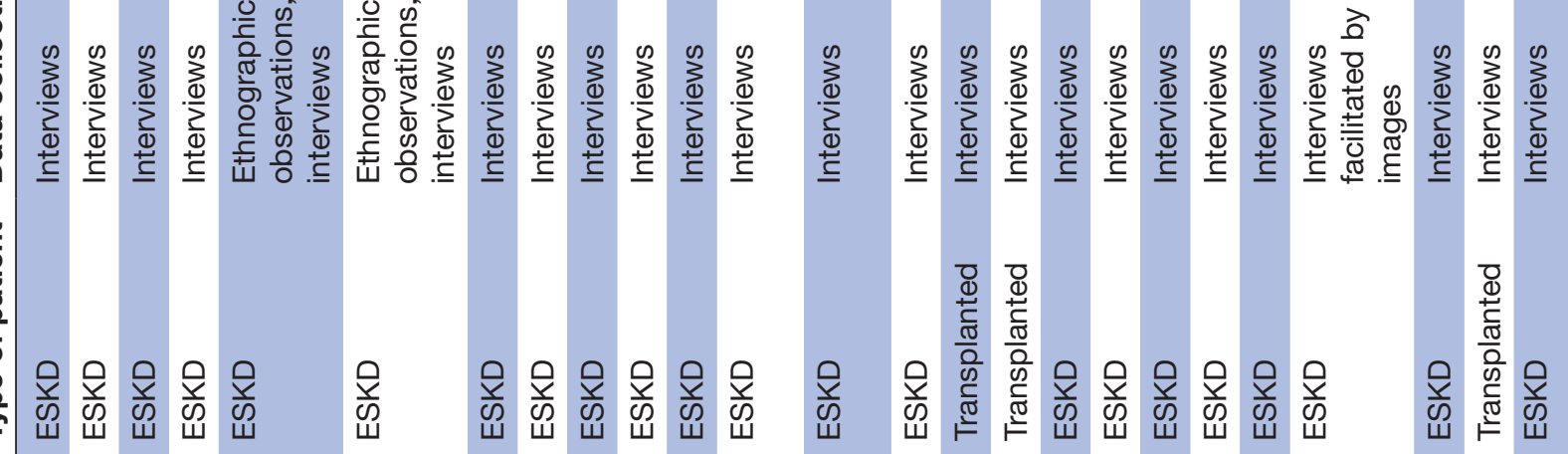

$\frac{\infty}{0}$

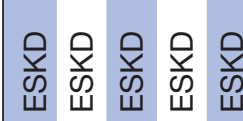

$\frac{2}{w}$

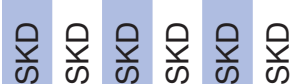

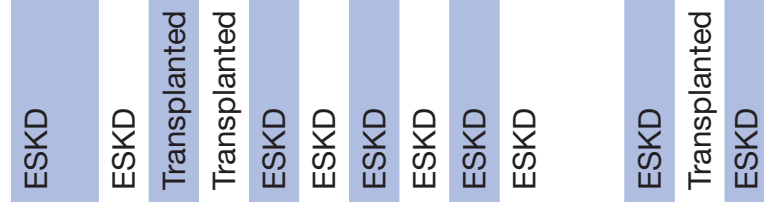

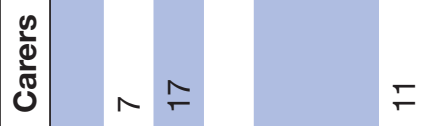

$\stackrel{n}{\stackrel{2}{0}}$

$\frac{2}{\pi}$

$\wedge$

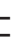

$\stackrel{+}{ \pm}$

$a \infty$

$\hat{m} \sim$

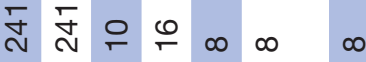

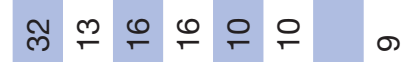

$\stackrel{\llcorner}{\sim} \stackrel{\circ}{\sim}$

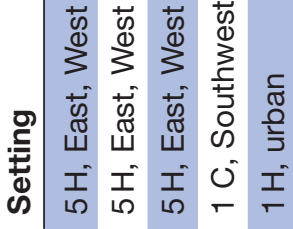

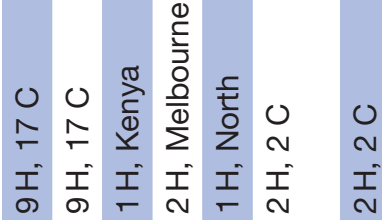

$\frac{\sqrt{2}}{\frac{1}{3}}$

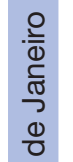

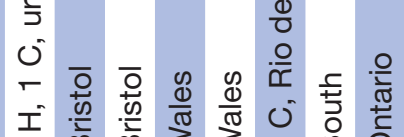

\%

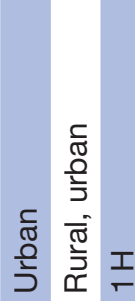

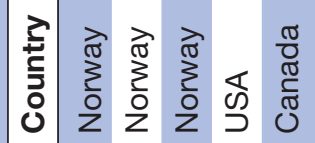

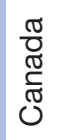

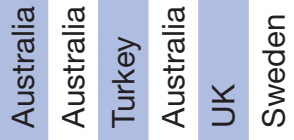

$\frac{1}{0} \frac{1}{0}$

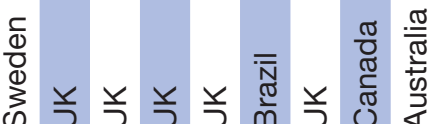

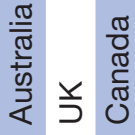

离

ஜำ ำ ㅇำ

ㄴ.

$\infty$ \&

¿্ঠ

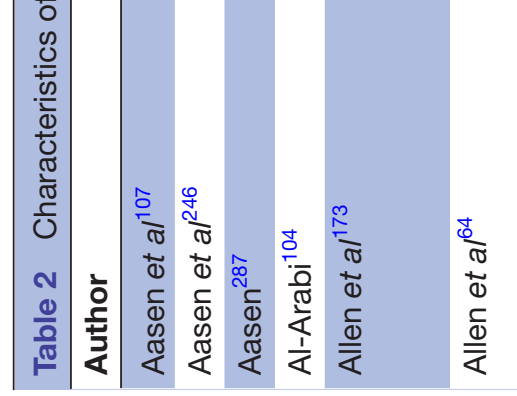

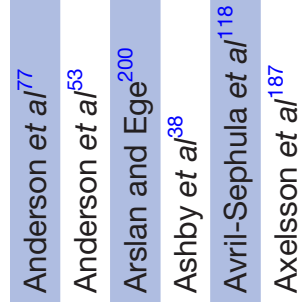
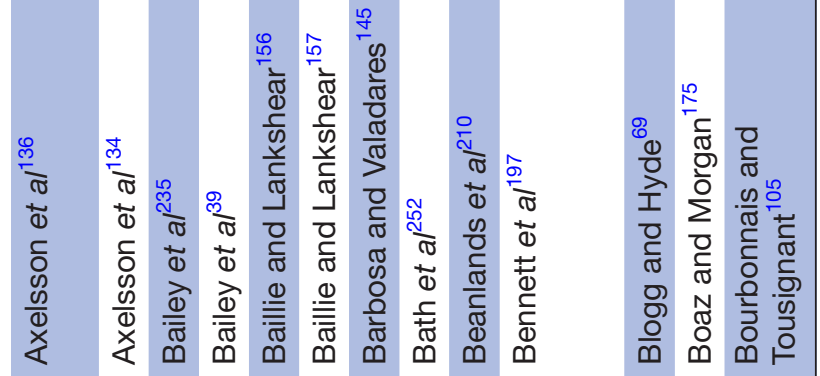

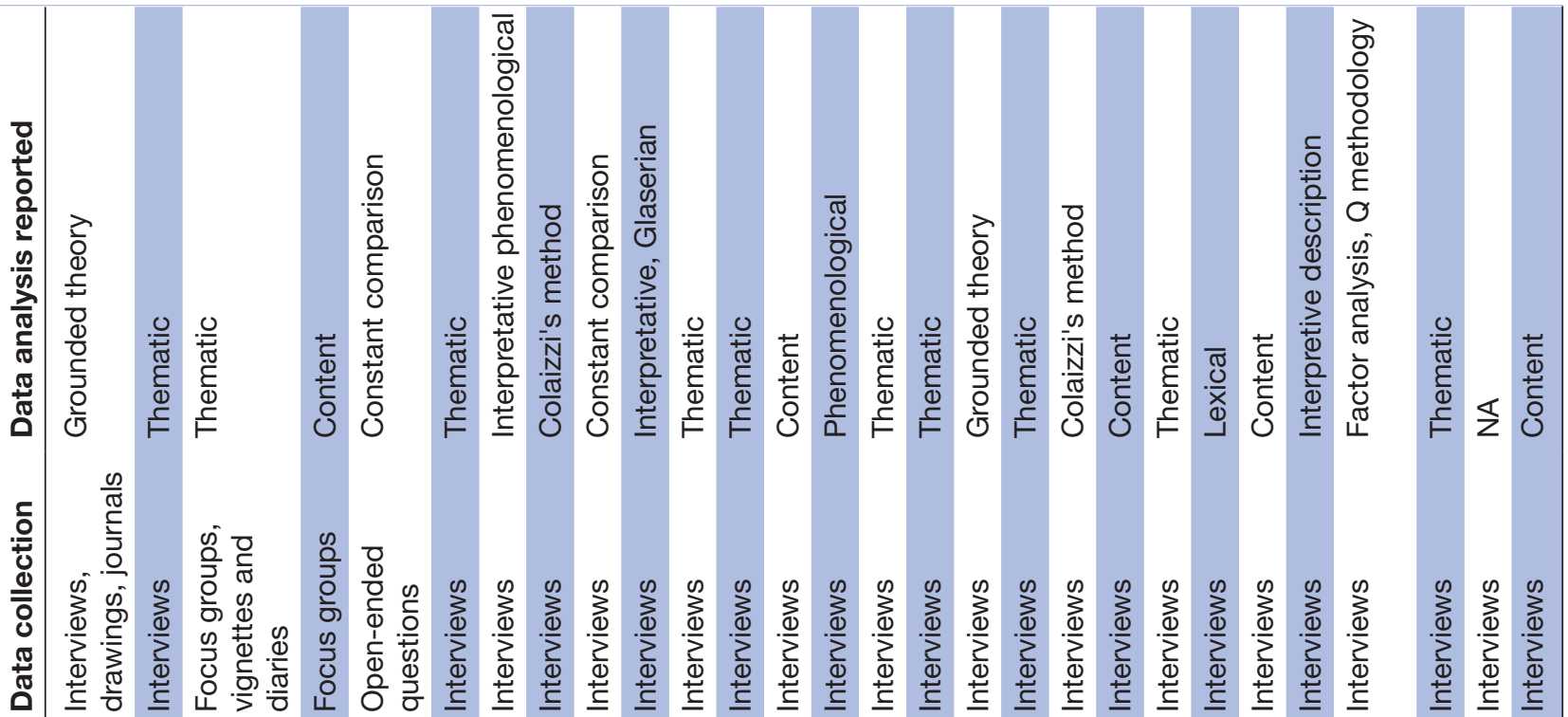

荬

$\frac{2}{0}$

ป

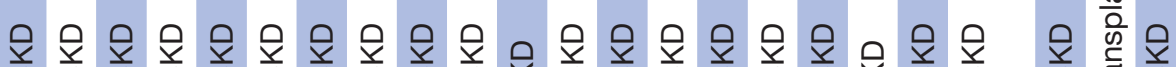

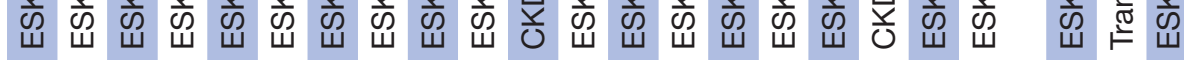

แั

$\stackrel{\infty}{\sim}$

$\stackrel{2}{N}$

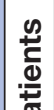

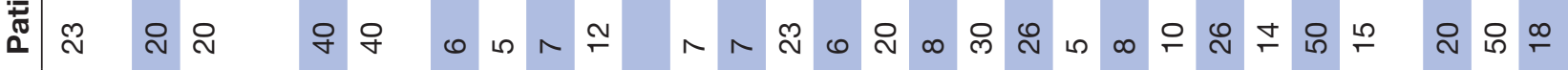

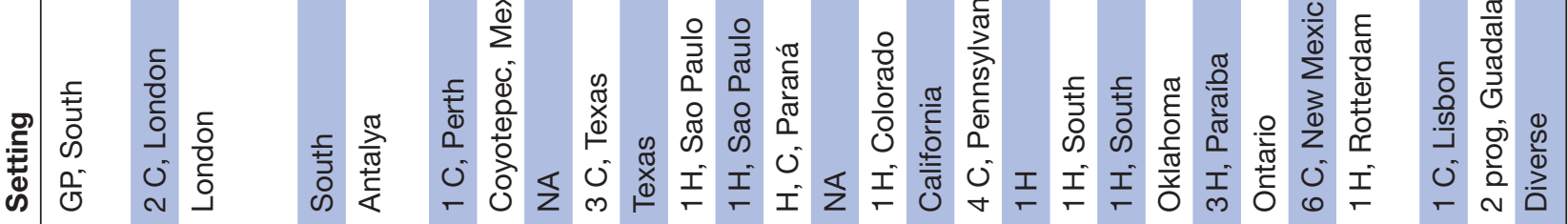

至

ฮ

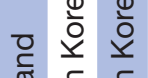

$\frac{\infty}{0}$

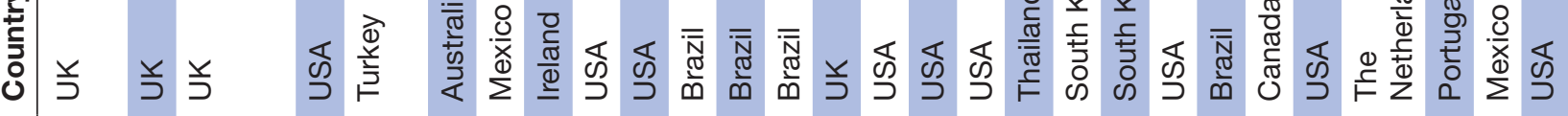

㐫

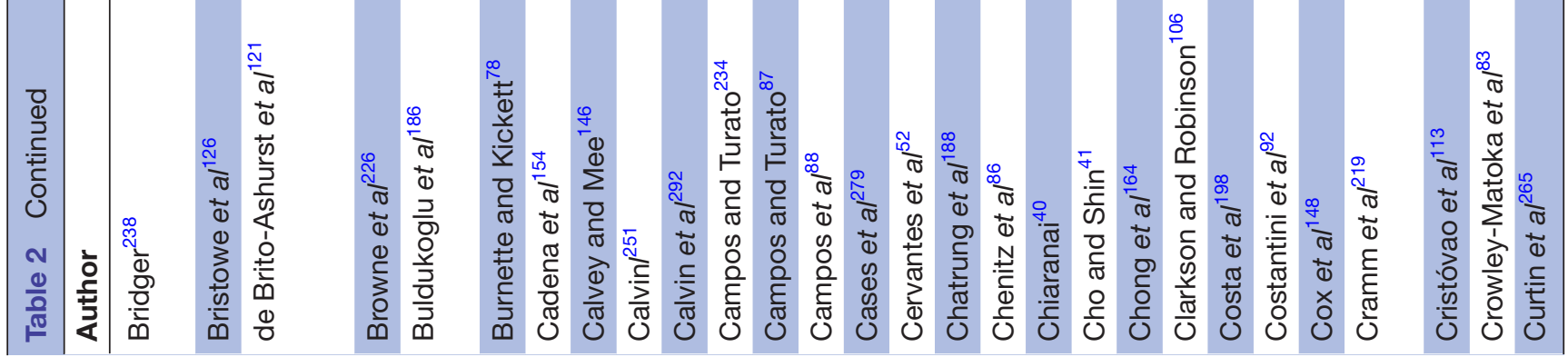




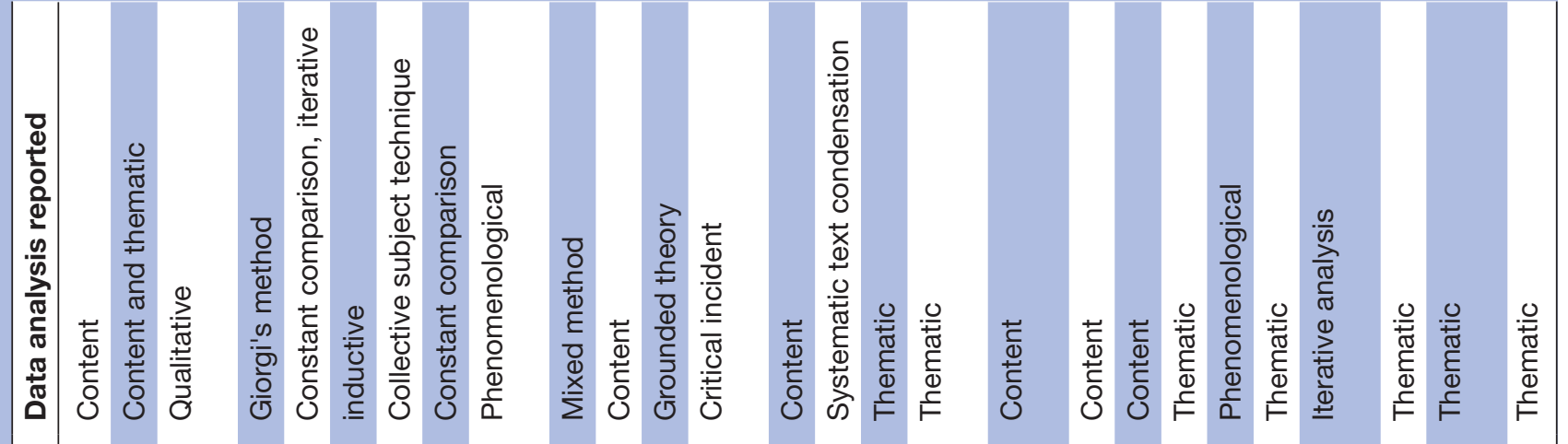

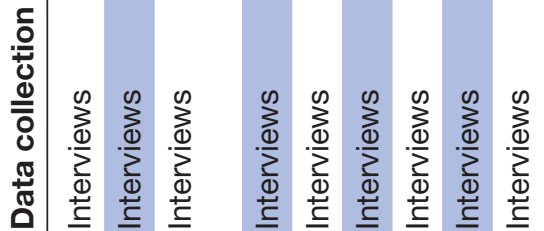

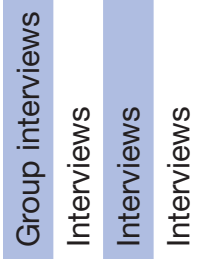

을 을

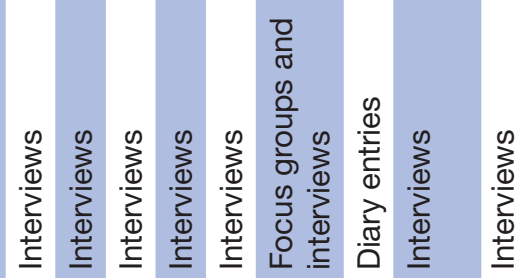

$\frac{0}{8}$

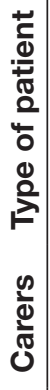

$\underset{\substack{d \\ \frac{0}{c}}}{\frac{0}{2}}$

$\frac{\sqrt{0}}{\frac{\pi}{\omega}}$

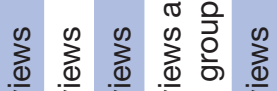

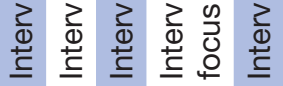

离 $\stackrel{\Phi}{\underline{\Phi}} \stackrel{\Phi}{\underline{\Phi}} \stackrel{\Phi}{\underline{\Phi}}$ 市

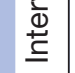

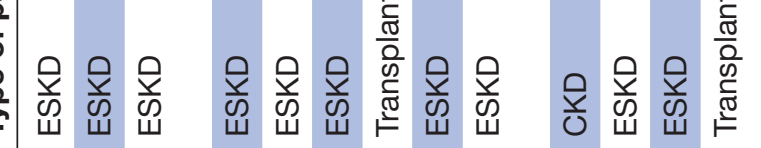

它

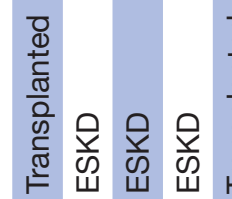

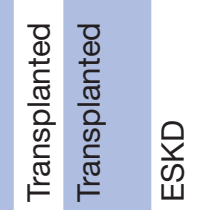

$\frac{\frac{n}{0}}{\frac{\pi}{\overparen{D}}}$

으

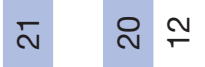

$\stackrel{\infty}{\infty}$

$\infty$

$\stackrel{\infty}{\stackrel{\infty}{ \pm}}$

产

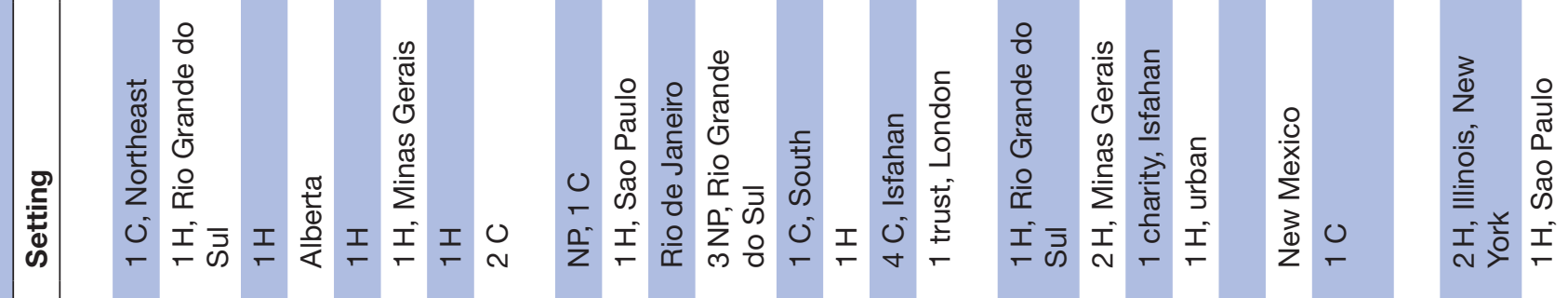
$\frac{\infty}{0}$

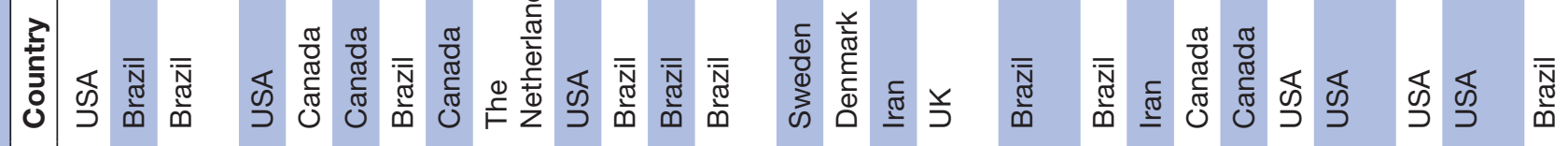

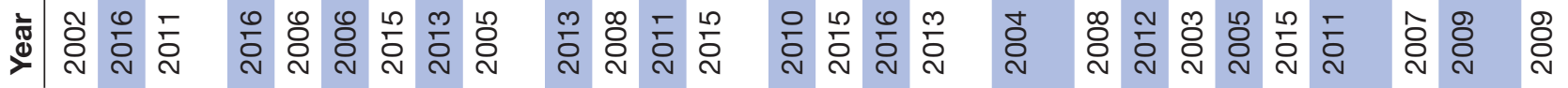

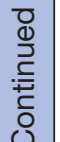

ลัก

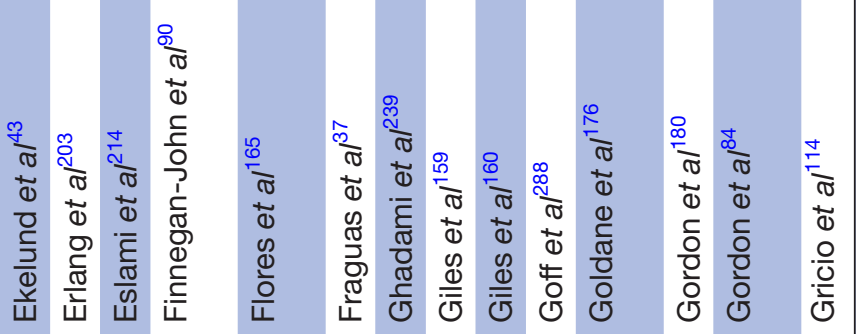



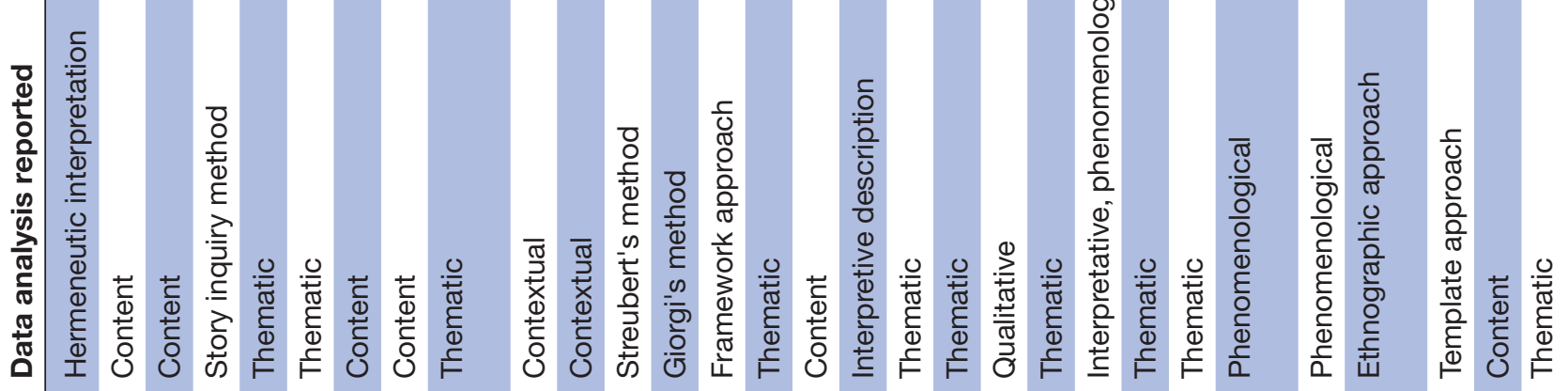

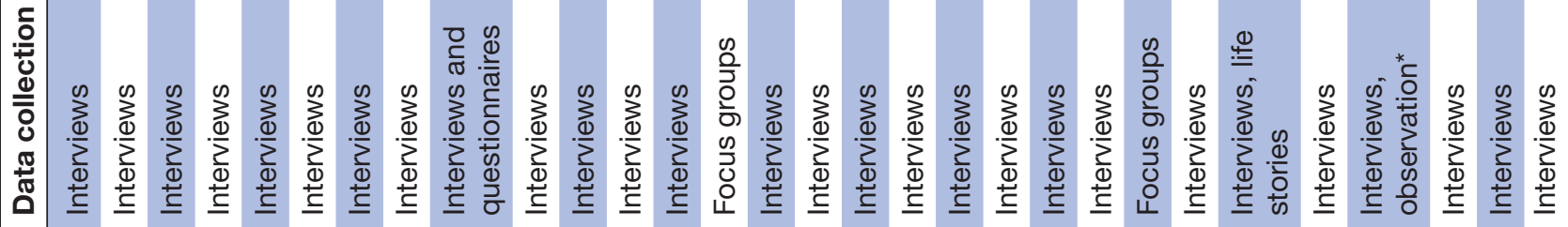

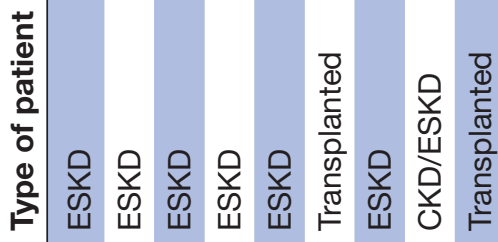

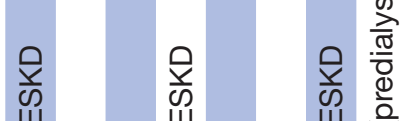

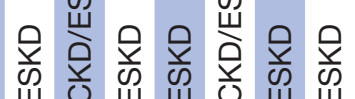

फ 흐 山

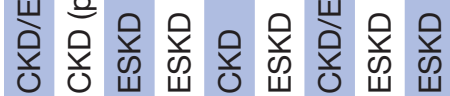

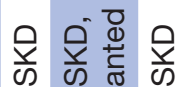
Ш

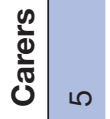

$\stackrel{0}{\circ}$

$\widehat{\infty}$

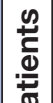

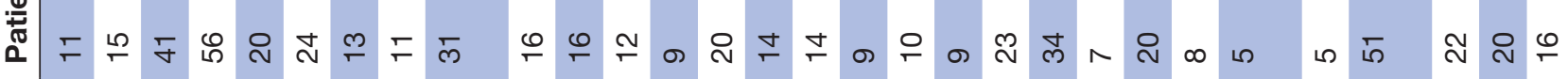

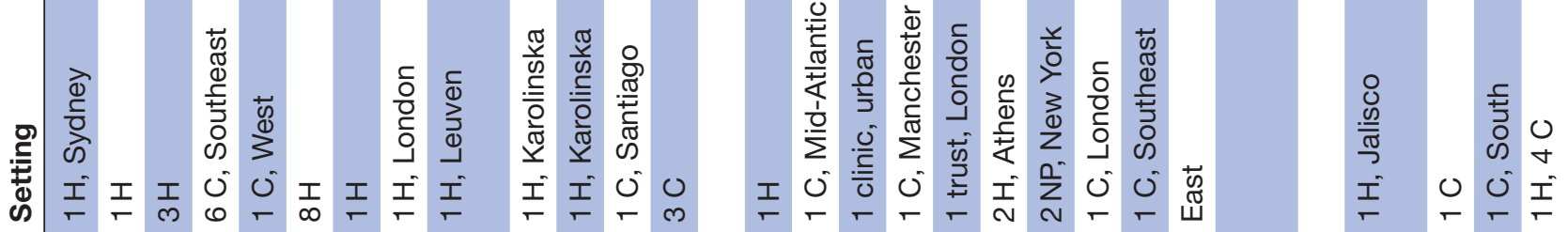

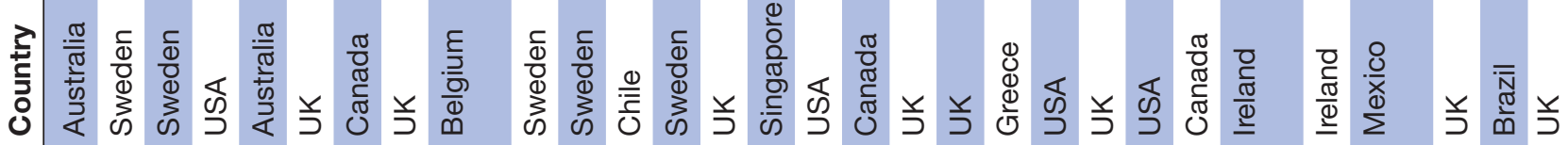
㐫

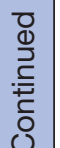

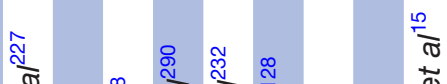

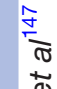

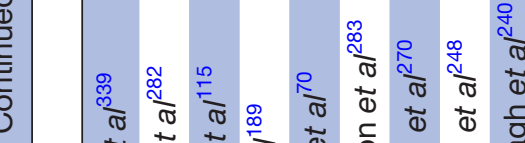

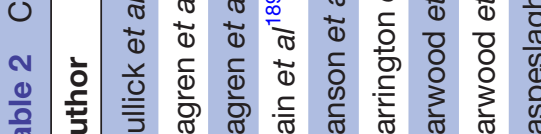

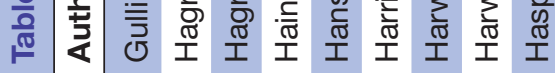

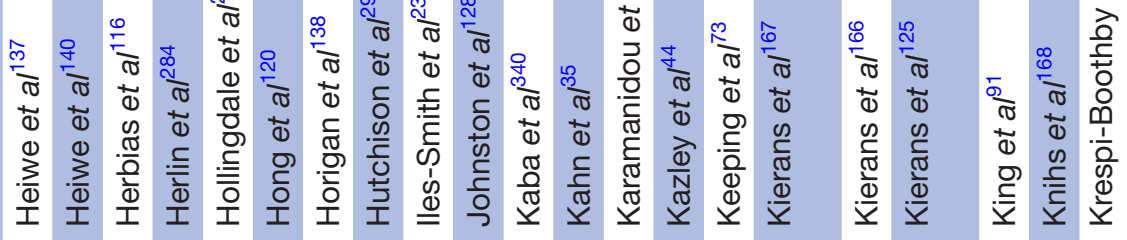



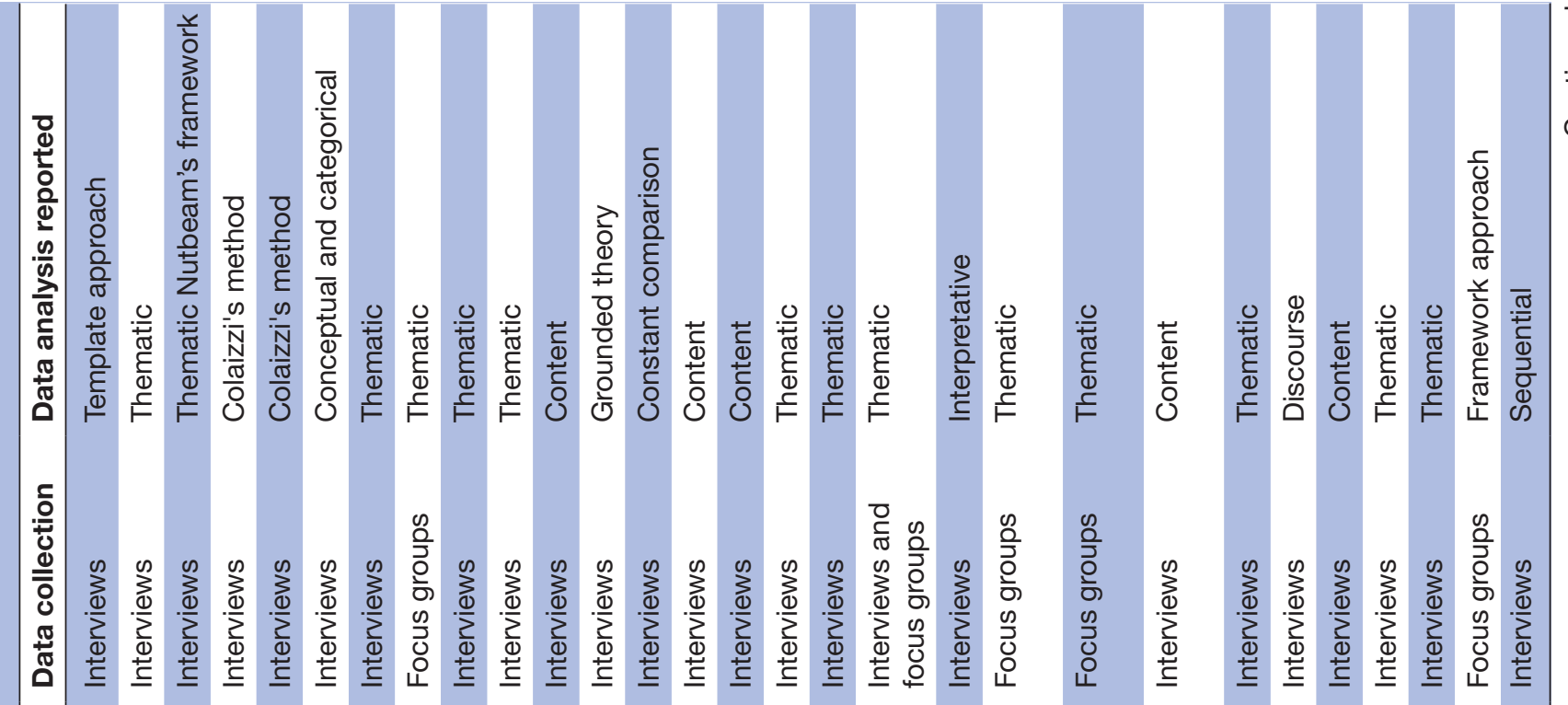

$\frac{\overrightarrow{\mathrm{z}}}{\stackrel{\mathrm{m}}{\mathrm{d}}}$

के

$\frac{0}{\text { के }}$

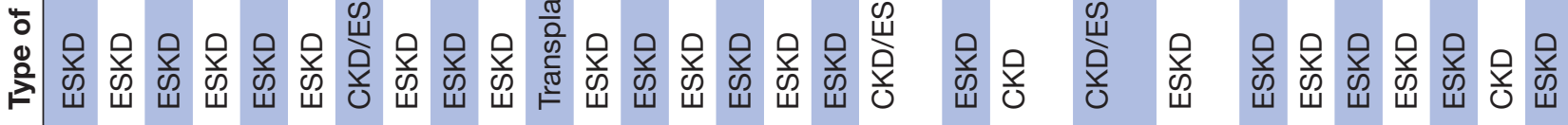

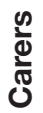

$\stackrel{\infty}{\sim}$

$\stackrel{\bullet}{\sim}$

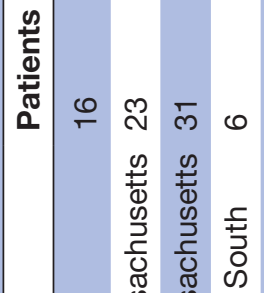

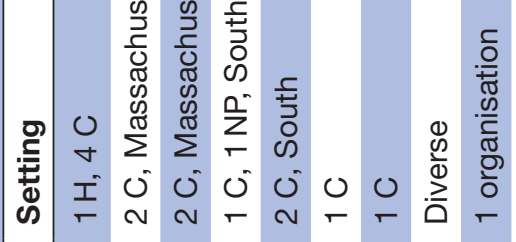

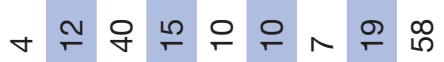

$\simeq \stackrel{\infty}{\infty} \stackrel{\infty}{\simeq}$

$\stackrel{\infty}{\longleftarrow}$ 우우 の

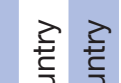

蛋

要

혹

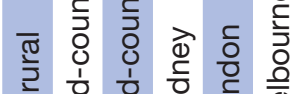

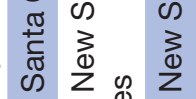

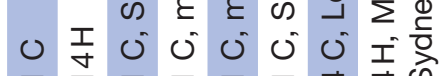

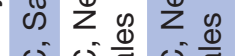

0

苃

옥

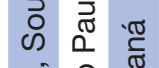

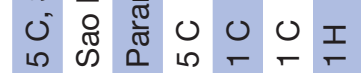

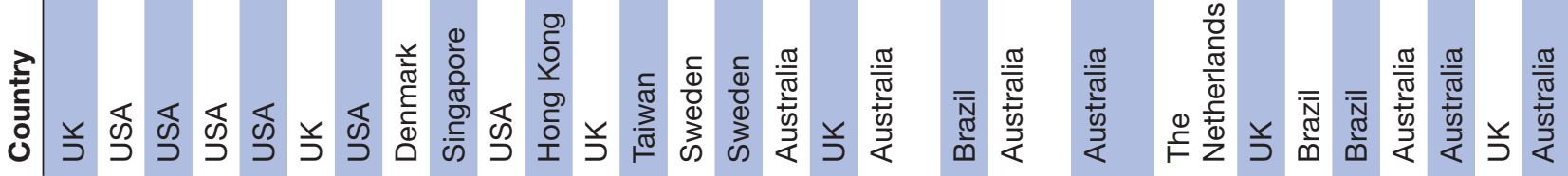

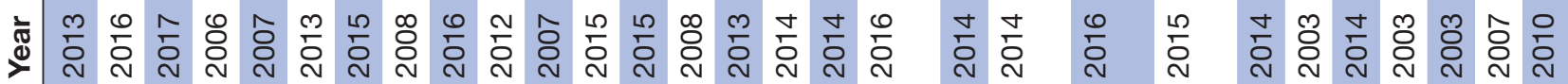

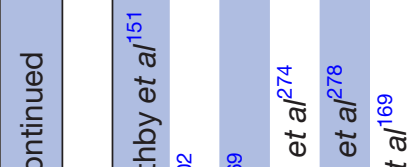

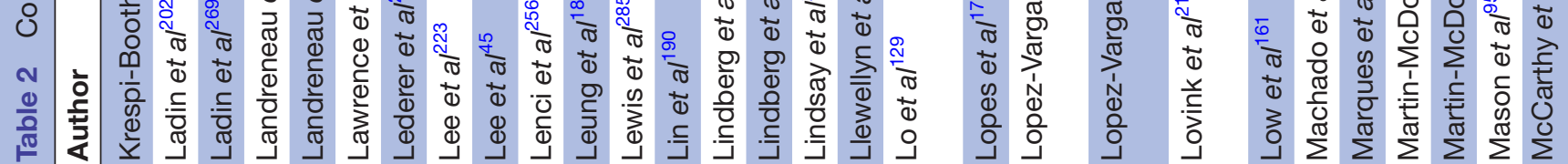


일

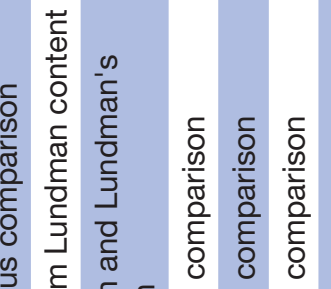

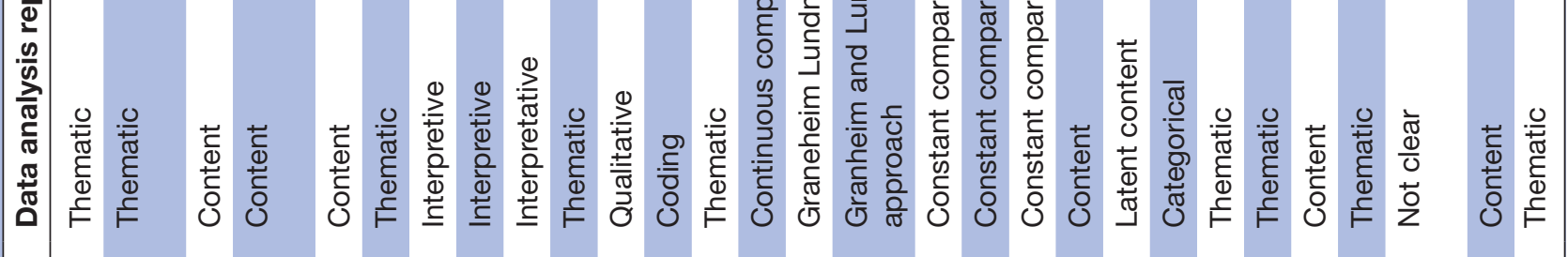

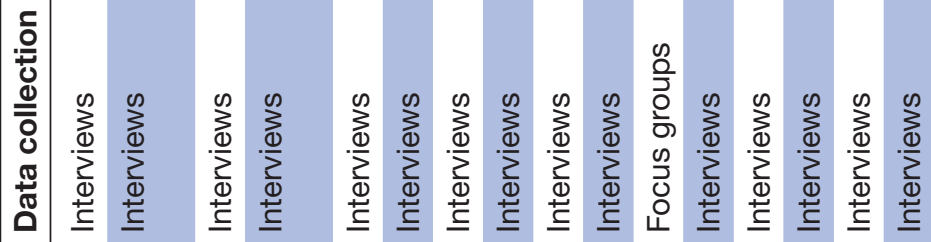

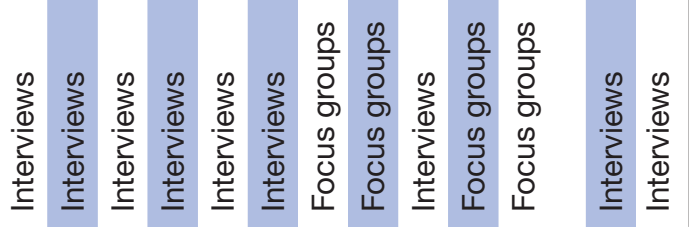

蒙

棓旁

ํํำ

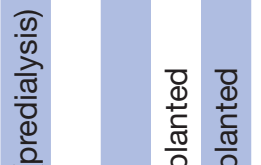

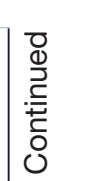

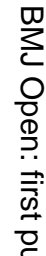

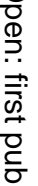

$\frac{\bar{\sigma}}{\Omega}$

क

$\vec{\circ}$

$\overrightarrow{\vec{\omega}}$

음.

レ

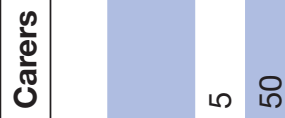

$\stackrel{ }{\leftarrow} \div \stackrel{ }{\leftarrow}$

$\stackrel{\leftarrow}{\leftarrow}$

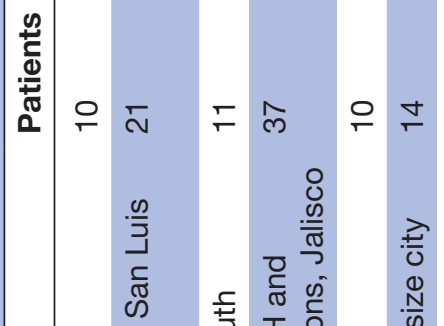

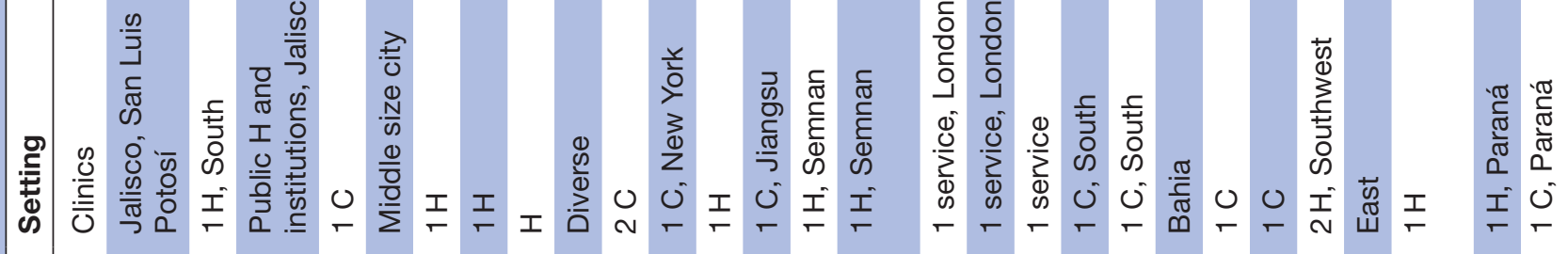

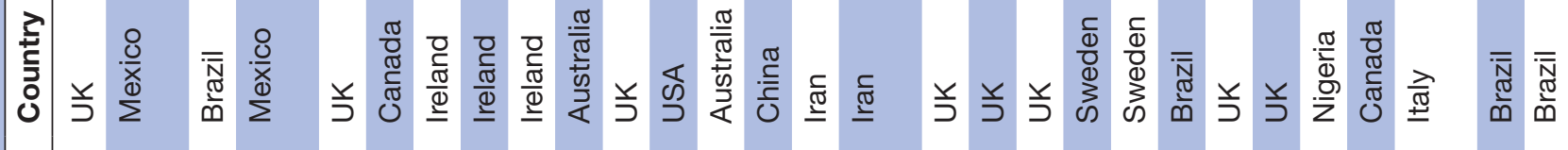

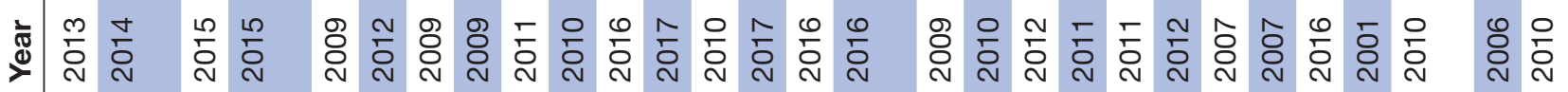

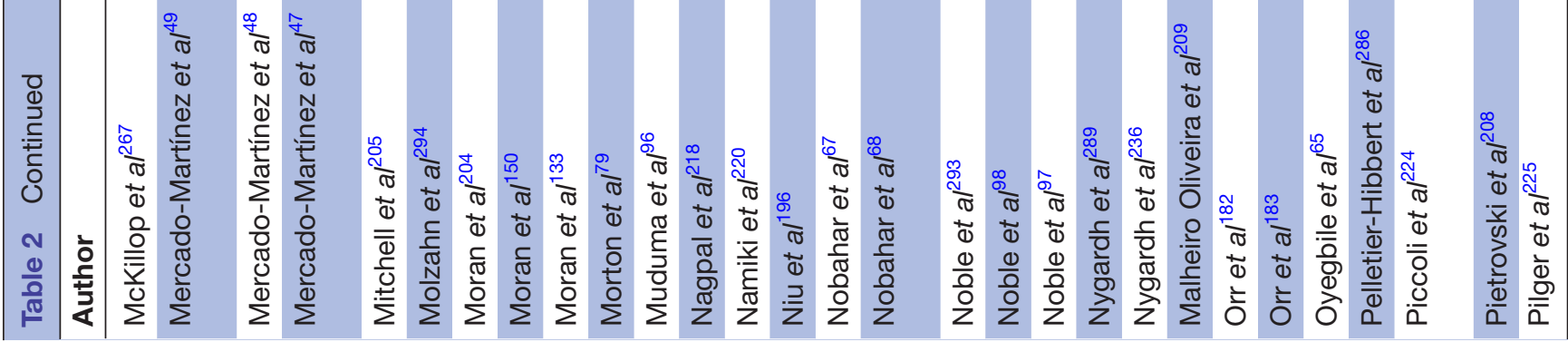


量
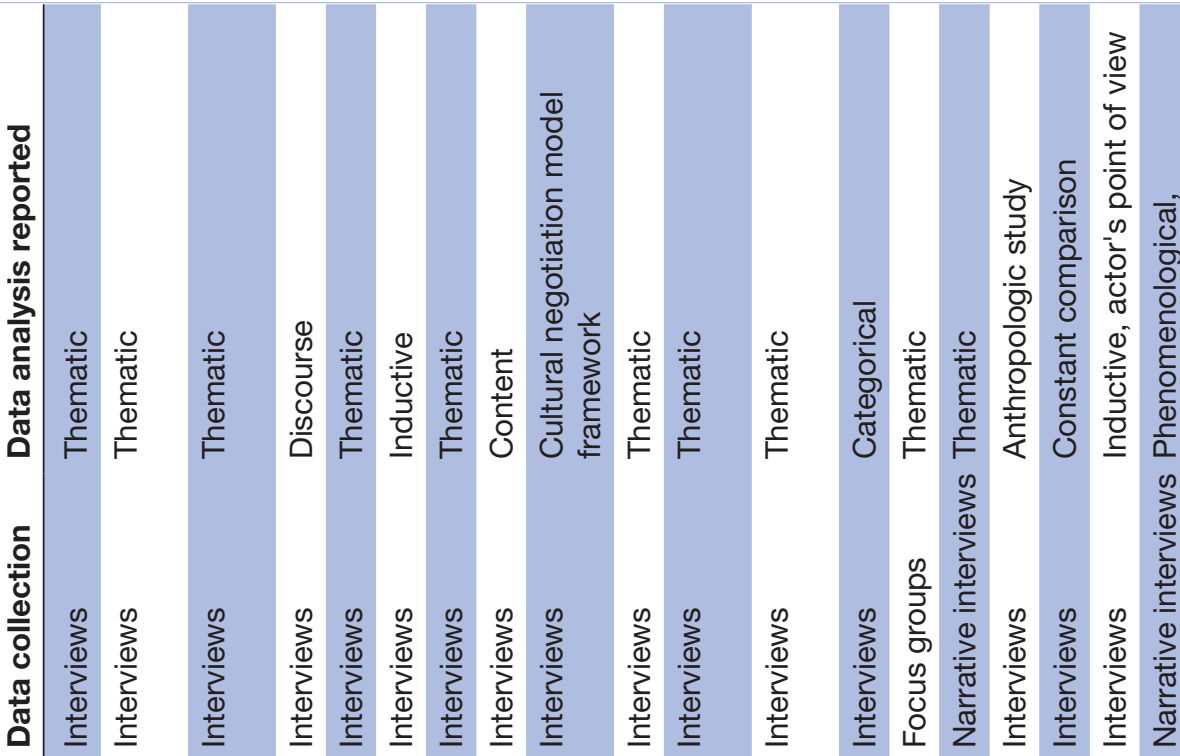

믈

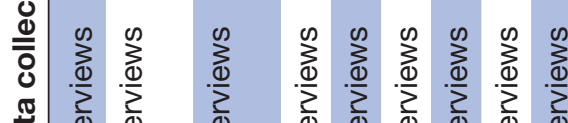

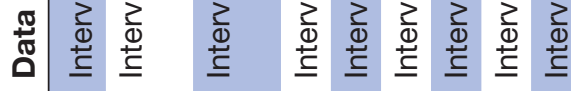

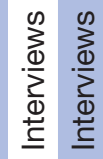

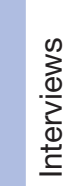

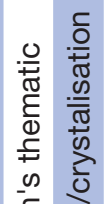

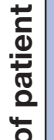

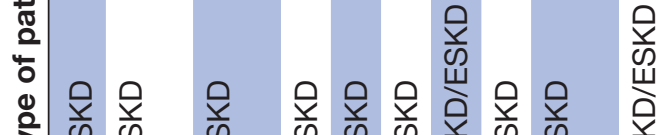

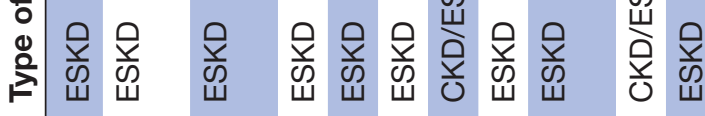

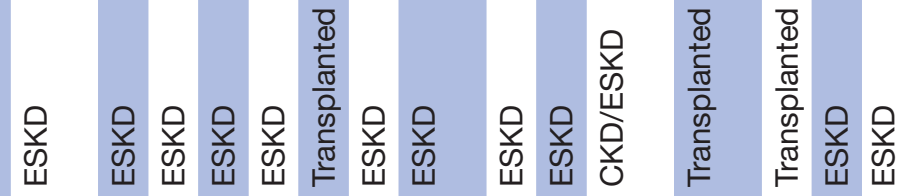

仓ั

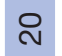

న

F

$\stackrel{\infty}{\stackrel{2}{ \pm}}$

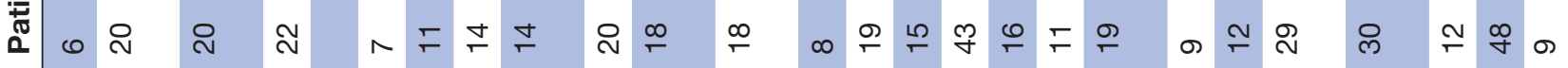

(1)

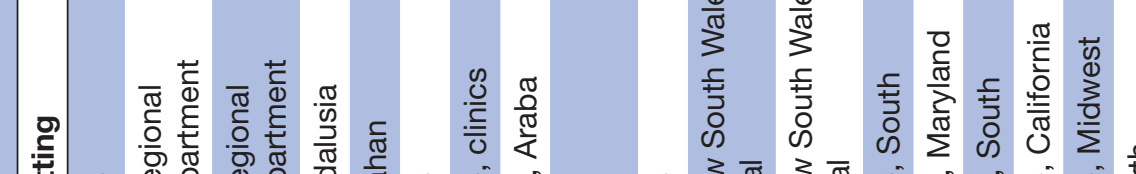

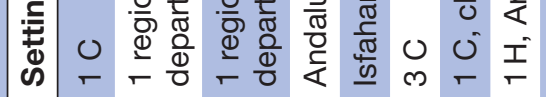

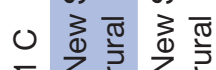

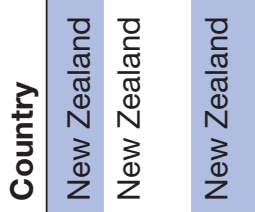

离

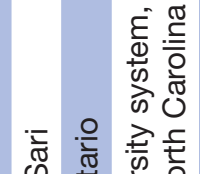

फ

うั

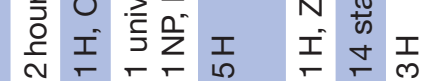

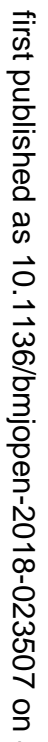

C)

票

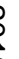

$\square$

乡

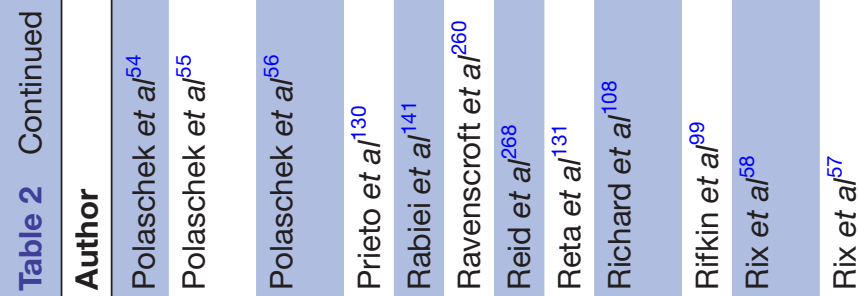

$\frac{\pi}{\frac{\pi}{2}}$

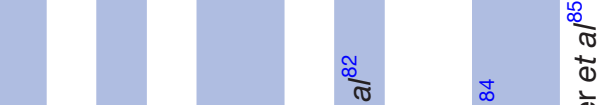

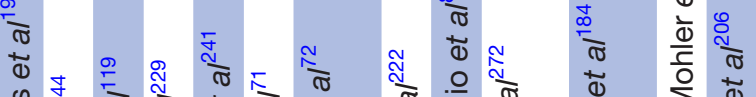

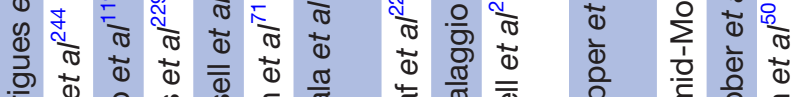

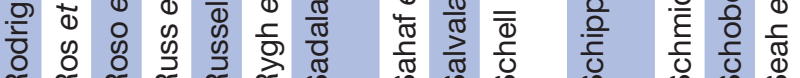

苂

웅

疍

$\frac{1}{3}$
$\frac{0}{3}$
$\frac{0}{0}$
$\frac{0}{3}$
$\frac{0}{3}$

ㅇํํ

옥

을.

ก

ก

₹

ำ 

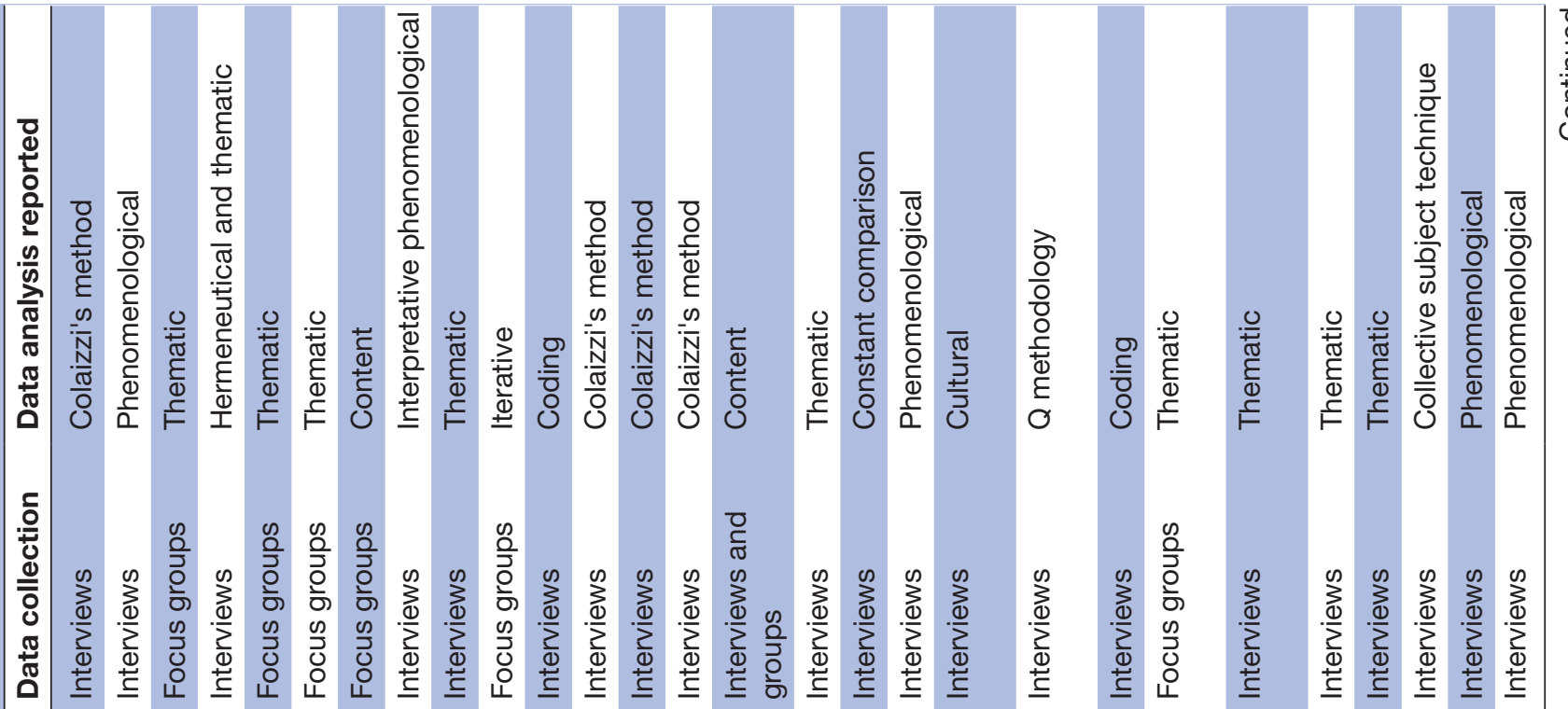

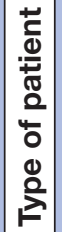

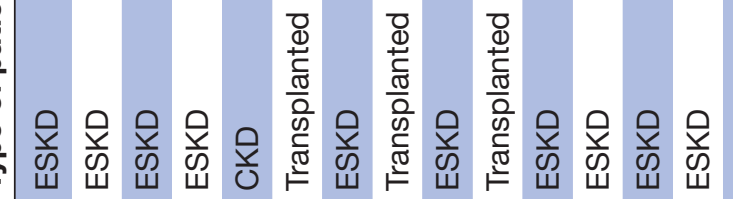

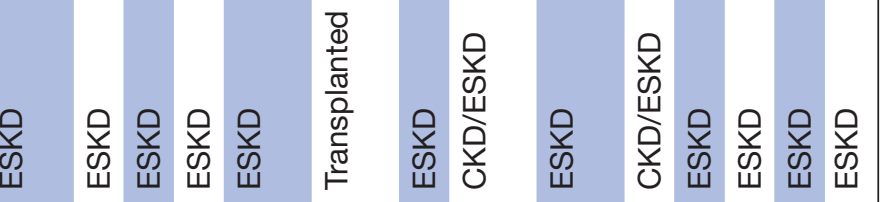

足

N

이두우



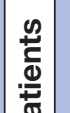

产

$\stackrel{ }{\sim} \stackrel{0}{\leftarrow}$ 으

$\stackrel{\oplus}{N}$

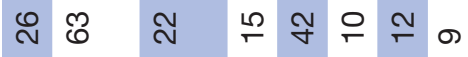

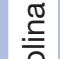

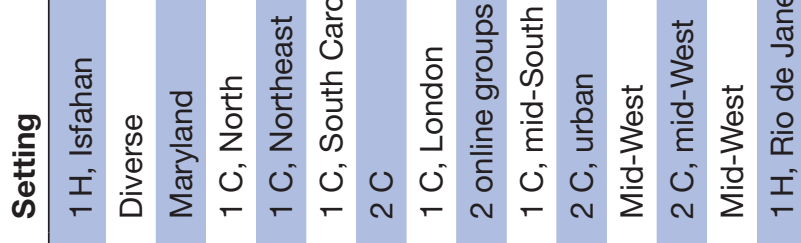

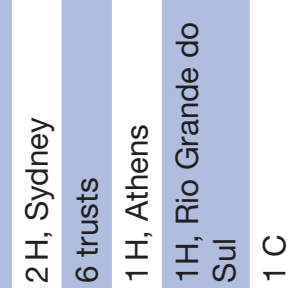

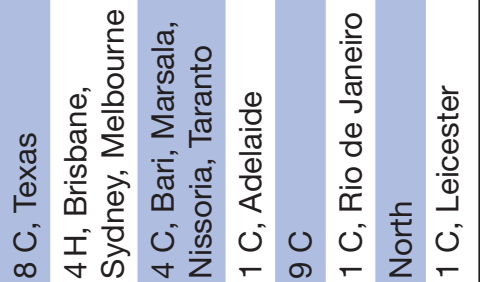

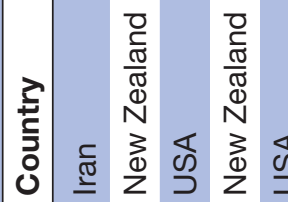

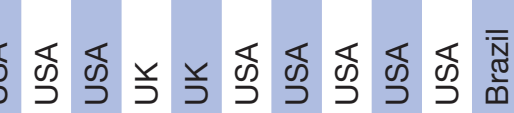

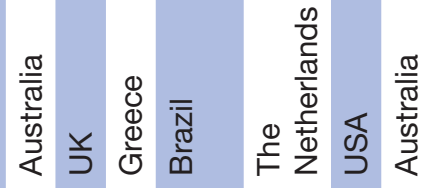

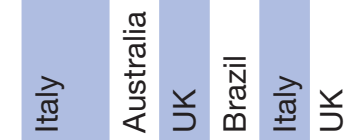

๘

0 in $m$

$\bar{\sigma}$

0 ( )

$\tau$ N $N$ N N N N N N N N

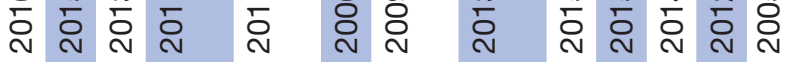

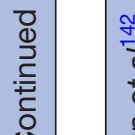

$\frac{\sqrt{2}}{\frac{\pi}{2}}$

ठั

ก

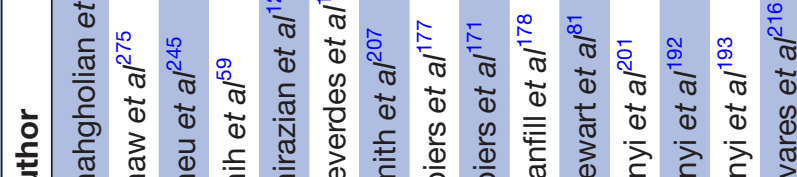

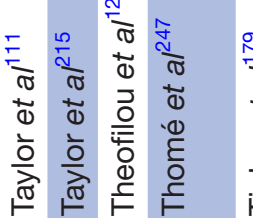

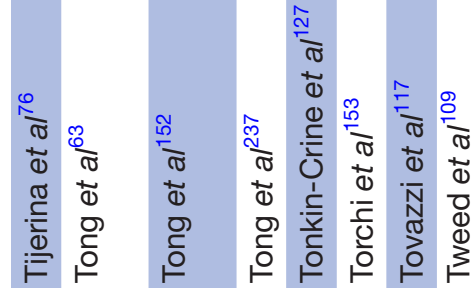

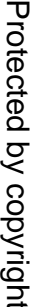




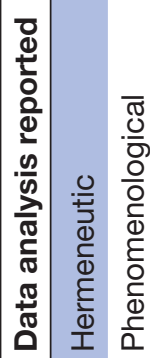

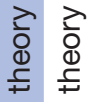

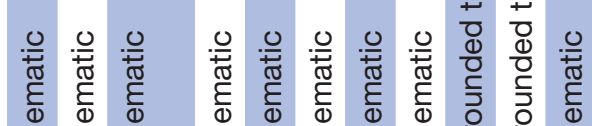

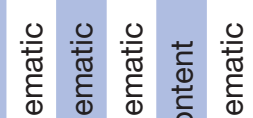

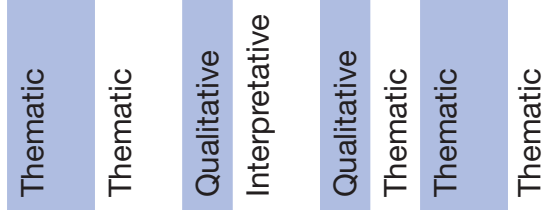

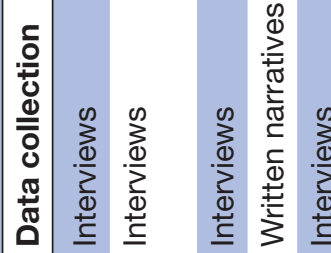

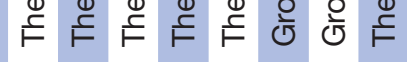

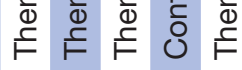

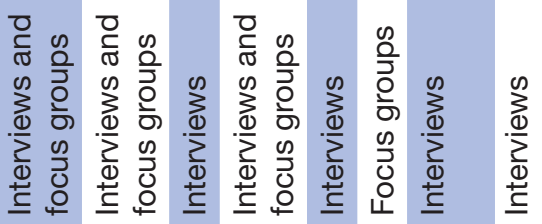

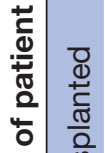

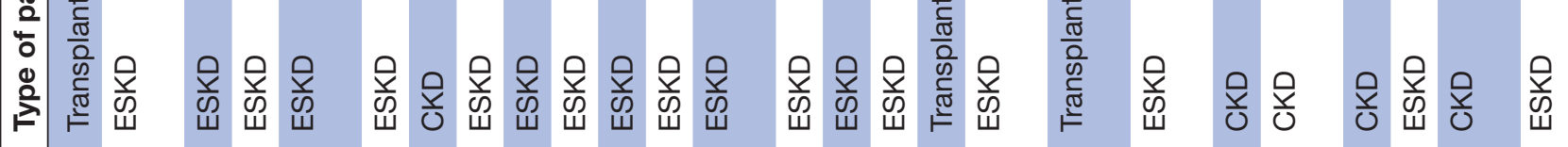

ֻั

の

$\therefore \bar{\sim}$

$\stackrel{8}{\ln }$

$\stackrel{2}{\square}$

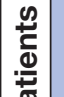

휴

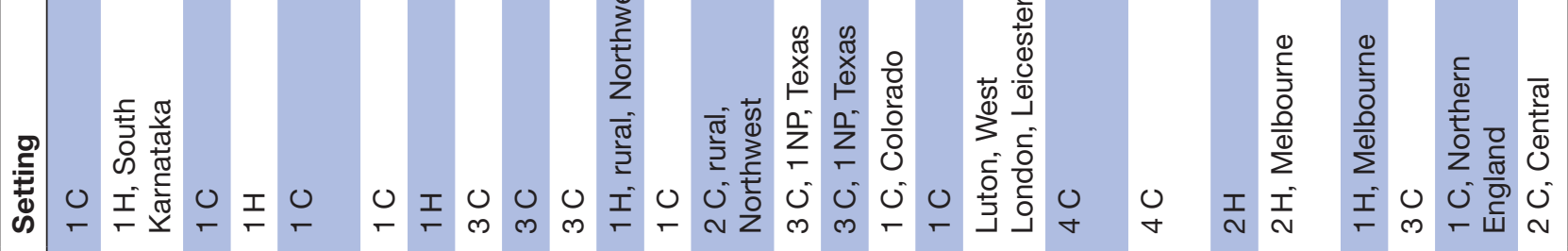

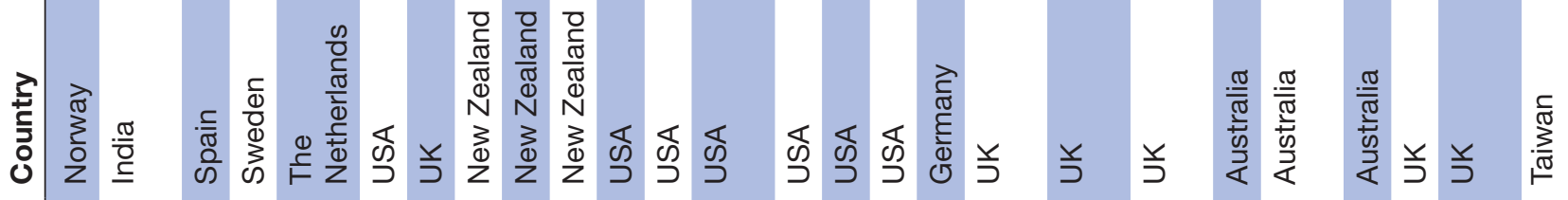

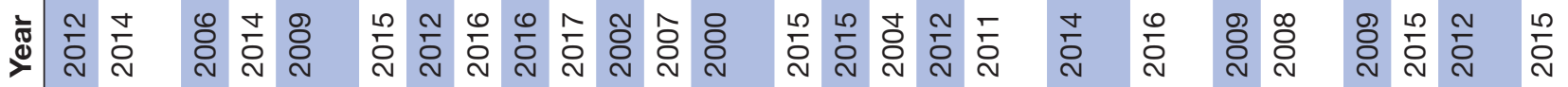




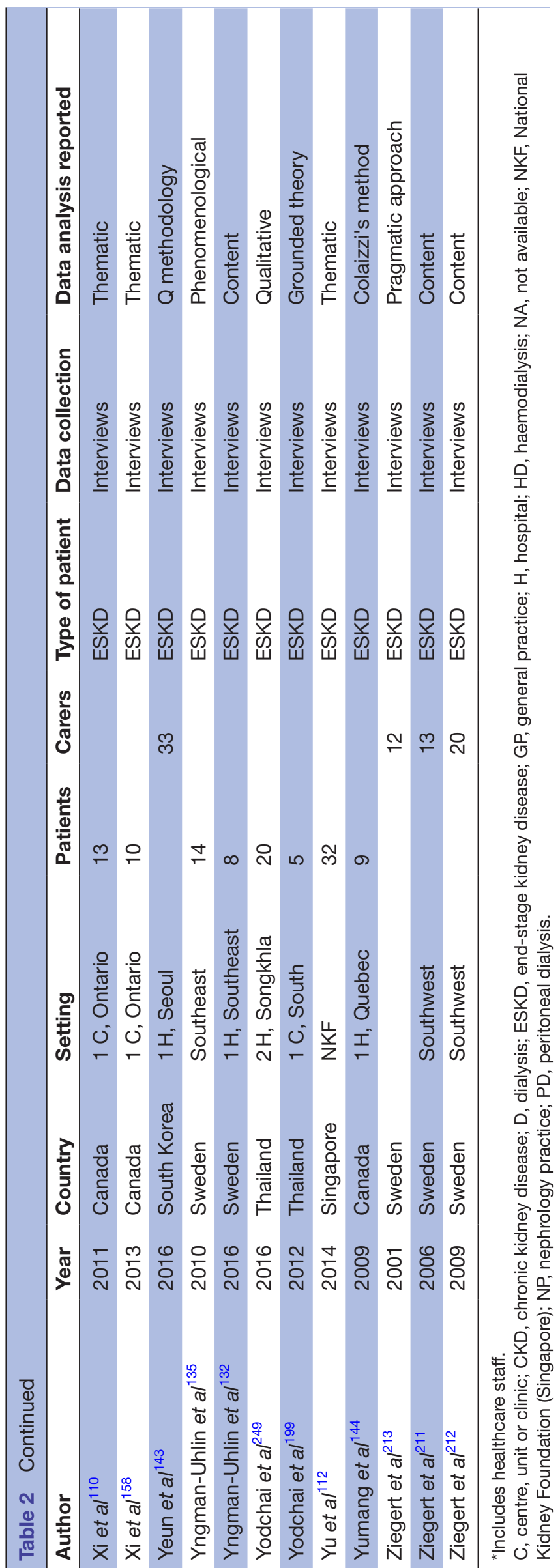

Box 1 Illustrative quotations

\section{Structural inequalities}

(Undocumented immigrant in US without access to scheduled haemodialysis) When you enter through the emergency department, you arrive in bad shape...you need to have a high potassium or they send you home even though you feel you are dying. Sometimes, you crawl out when they decide to not do dialysis. You eat a banana because it is high in potassium even though you may die and you go back and wait and hope that they will do dialysis so that you don't feel like you are drowning and so that the anxiety goes away (American patient). ${ }^{52}$

My mother got some help from DIF (Mexican social assistance office), it was five haemodialysis sessions; when there was no session left, we went to a private centre, there is a foundation there and they helped us... they gave me eight sessions. After that, my mom went to DIF in Zapopan again and they sent us to DIF in Guadalajara. We got some help there (Mexican patient without coverage). ${ }^{47}$

\section{Workload}

Sometimes I have to sit and wait at least an hour and I have to call and say my ride is not here yet, which makes me late getting there, which makes me late getting on the machine, which makes me late getting off the machine. And then... coming to pick you up, if you're not ready when they get there, they will leave you and you'll have to sit and wait and wait and wait (American patient). ${ }^{86}$

It is always in the back of your mind that it (the transplant) will fail, at times. And I think if anything that makes you more inclined to comply with your treatment, comply with your medication because at the end of the day if, you know, if you do the utmost that you can and you take your medicine and you go to your follow up appointments, then there's hopefully less chance of it failing in the long run (woman, 3 years+post-transplant). ${ }^{175}$

I suppose mine being genetic. It's been very difficult to find what kind of diet you're supposed to follow. You read one bit of information and it tells you this and you read another bit and it tells you don't eat that, which the other one said you must eat. there's no clear guideline on what it is you can or can't eat (man, 38 years, CKD stage 3 ). ${ }^{94}$

It was a lot more work because of all the things that you had to learn... I don't eat out anymore... It's tough taking so many pills (patient with CKD). ${ }^{92}$

\section{Capacity}

Before she left (pause) when everything was happy and happy sort of thing, you know, I think it was-she was going to give a kidney to somebody else and somebody else was going to give a kidney to somebody and somebody was going to give a kidney to me-like a triangle... she was willing to do that. It didn't happen, um (pause) 'cos she left (UK patient). ${ }^{39}$

it's a kind of tiredness that you wouldn't wish on your worst enemy... when you can't read, you're too tired to watch the telly, you're too tired to do anything, because your brain is so tired like all of you... it feels like you're kind of hollow inside... like it's only a kind of shell that's functioning. ${ }^{137}$

Well about five years ago, I went to the hospital because I wasn't feeling good and they took my blood pressure and it was 200 over something...Then while they were trying to get my blood pressure down, they said something about my kidneys. And I didn't know the connection between high blood pressure and kidneys (Evan, African-American male, 50, CKD stage 3). ${ }^{35}$

It wasn't till about 2 years ago, until I fully understood and I've had the kidney disease from the age of 15 , what exactly my (kidney) function was and I got a fright. No one had ever told me (man, 38 years, CKD stage 3 ). ${ }^{94}$

Continued 


\section{Box 1 Continued}

\section{Control and decision-making}

I have free rein of whatever days I want to take off. They don't tell me when I have to dialyse or when I can't dialyse. Everything is under my control. That's what I like (talking on home dialysis, patient from Canada). ${ }^{158}$

If I'm going to feel this bad for the rest of my life, do I just want to end it now? (woman, 40s, CKD stage 4). ${ }^{63}$

\section{Carers' involvement}

I just sit here like a robot. Nurses asked me to buy items that my mother needed. They never told me why she needed them. They ordered me to pay for dialysis, laboratory investigations and other things. I don't like it when I do not know the reason behind my actions. I am sad to see myself as a fool being tossed around (caregiver from Nigeria). ${ }^{65}$

\section{End of life}

Then (the home care nurse) said 'Well you haven't got to go on. We'll make it quite peaceful for you to pass on'. They can tell you, but it's your body. It's up to me to decide what I want to do (patient from the UK). ${ }^{205}$ I have heard (about) a lot of people that died on dialysis and had strokes on dialysis... Once I sit down there, I don't know whether I'm gonna come out alive or dead (Berta, aged 45 years, blind amputee, dialysis patient for 18 months). ${ }^{76}$

I think about (death) everyday. I mean you can't help it. I know that it is a terminal illness and it's not going to get better and that there is only one way out (wife of a Canadian patient on peritoneal dialysis). ${ }^{286}$

CKD, chronic kidney disease.

risk, whatever their treatment modality, as in the case of many undocumented and uninsured immigrants in the USA. $^{35} 47-495266$ In countries with poor healthcare infrastructure, patients reported shortage of public specialised hospitals, long delays to undergo examinations, limited number of haemodialysis machines available, lack of ward space or poor bed conditions in hospitals, for example, poor hygiene, worn-out mattresses, shortage of linen; to avoid delays, patients sometimes had tests performed by private providers. ${ }^{4050606768}$

When home dialysis was available, patients had to pay for transport to training, appointments and other check-ups; moreover, some equipment, supplies, increased utility bills and home modifications represented unexpected expenses. ${ }^{51536169-73}$ In countries with coverage of RRT, for patients whose first language was different from that where treatment was received, as in the case of migrants, communication was a barrier for discussions with healthcare professionals; family members and neighbours acted as translators at appointments. ${ }^{53-76}$ Where language was shared, communications between clinicians and patients of different ethnic origins-for example, Australian Aborigines and New Zealand Maoris-was often itself a source of conflict and disadvantage, because of prejudice. ${ }^{53}$ 57-59 $77-82$

In some countries, the transplantation procedure could be particularly expensive, even at public hospitals. ${ }^{3547-49} 6683$ Moreover, patients sometimes found that the expensive immunosuppressants necessary after the transplant were not covered by their insurance; other patients who obtained information about the high costs of immunosuppressants and realising that they could not afford them, were forced to continue with dialysis until it failed. ${ }^{49-83}$ In Mexico, structural constraints resulted in transplanted patients being sent back to small peripheral clinics with no transplantation expertise, increasing the risk of iatrogenic or poorly managed complications. ${ }^{83}$

\section{Housing conditions}

Unsuitable housing was a barrier to home dialysis if it could not accommodate equipment, and was impossible without an adequate electricity supply. ${ }^{51} 61$ In rented accommodation, landlords might not approve of necessary modifications. Home dialysis was not a treatment option for those with no fixed abode..$^{51617086}$

\section{Employment status}

Patients who were physically able to continue working often had informal or temporary jobs, with diminished income; others were forced into unemployment, leading to new financial problems. ${ }^{39} 455260697287-91$ Unemployed patients in the USA were covered by government or state schemes; however, this coverage either diminished or ceased if they found work with a new insurance. ${ }^{35} 52$

\section{Patient workload}

\section{Self-care}

People with CKD and ESKD had complex medication regimens managed through dispensing aids, daily activities associated with medication taking such as meals, family support or a combination of these. ${ }^{40} 467186$ 92-106 Anticipating dialysis, patients underwent vascular access, a way to reach the blood for haemodialysis, undergoing minor surgery and care needed to be taken to prevent infections or clotting. ${ }^{66}{ }^{107-110}$ To care for their vascular access, patients kept the access area clean, changed bandages, restricted themselves from lifting heavy objects and were alert for pain or hardness in the area. ${ }^{108} 111$

Patients controlled their diets and fluid intake between dialysis sessions, and managed food cravings and thirst with strategies such as thinking of the potential detrimental consequences of drinking water, avoiding thoughts and behaviours that could trigger thirst and modifying social activities to minimise exposure to hot weather, social pressure and temptation to intake certain foods or fluids. ${ }^{46} 63$ 112-120 Women also faced potential family conflicts if they followed prescribed diets. ${ }^{462}$ 121-124 In certain cultures, including immigrants who preserved their customs in other countries, the perceived association of a rich diet and wealth acted as a barrier to adherence to a restrictive diet, essential to self-care, as patients feared being stigmatised as poor. ${ }^{62121} 125$

\section{Travel and time management}

People with ESKD travelled to haemodialysis centres three times a week, received treatment for several hours and then transported themselves home again; very often, transportation represented a problem for 


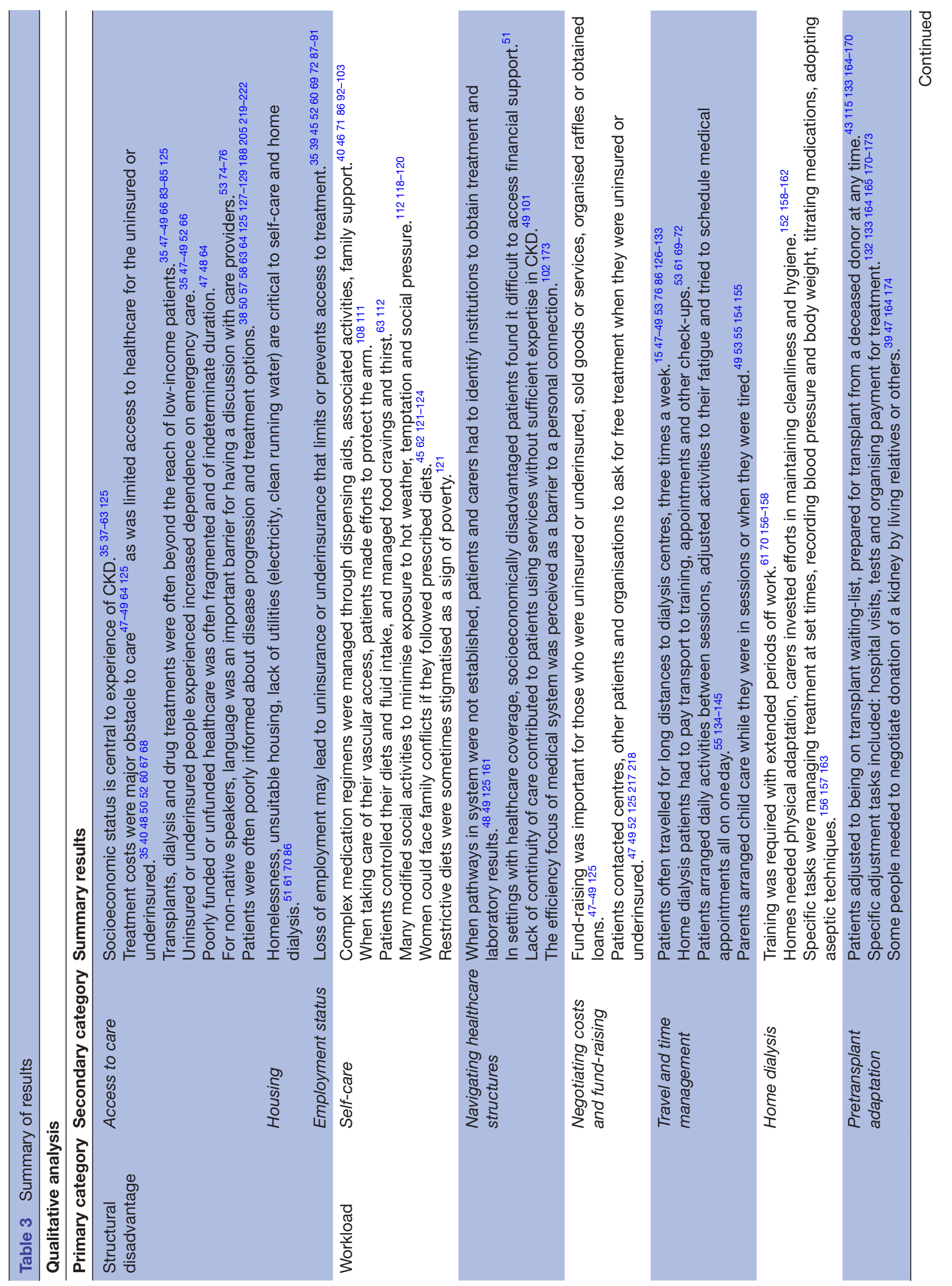




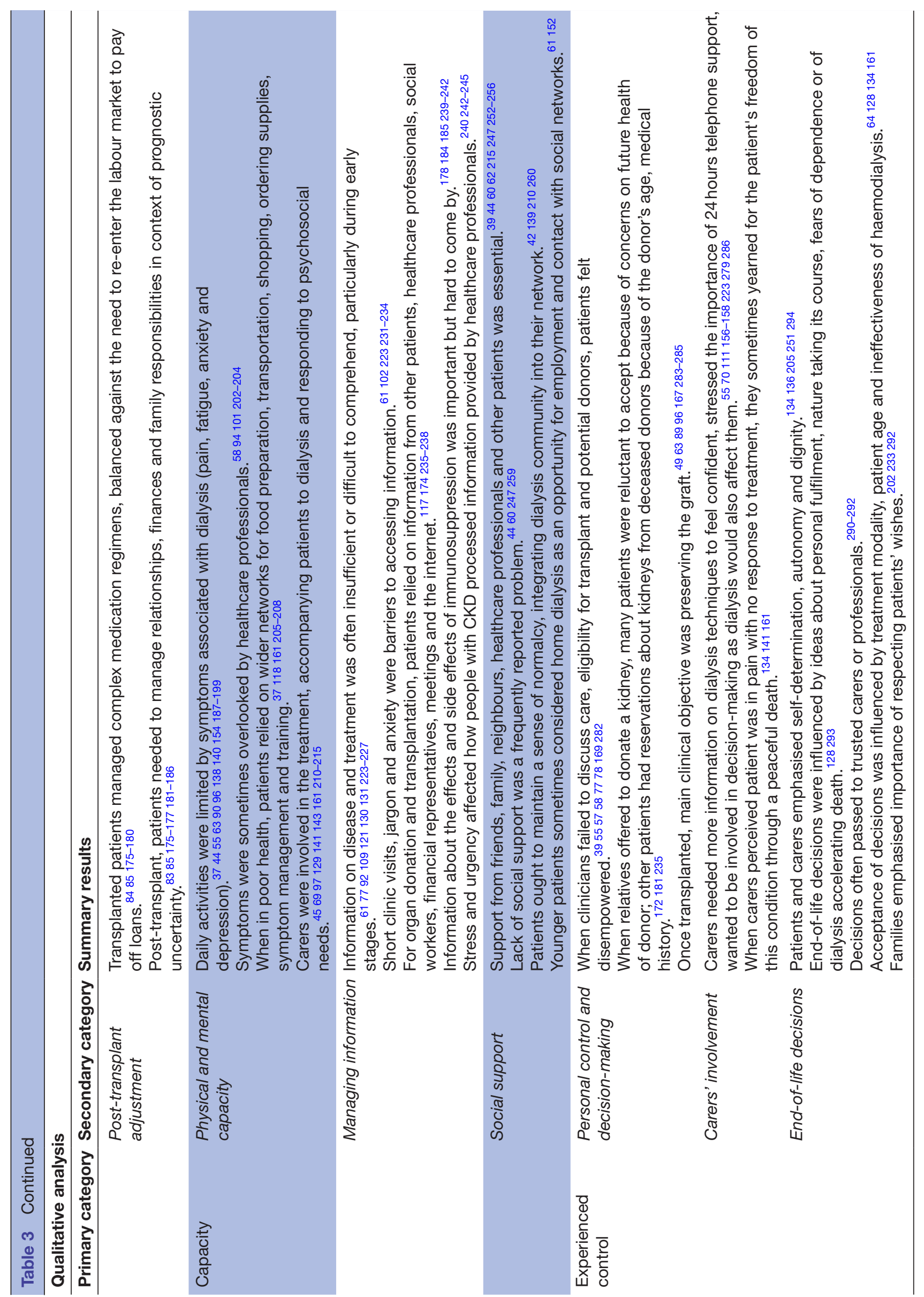


Table 4 Main challenges related to burden of treatment

\section{Challenge}

Limited access to healthcare for the uninsured or underinsured.

Dialysis, transplant surgery, immunosuppressive drugs were often beyond the reach of low-income patients.

Healthcare was often fragmented and of indeterminate duration for the
uninsured or underinsured.

In settings with healthcare coverage, socially disadvantaged patients found it difficult to access financial support.

Fund-raising was important for those who were uninsured or underinsured.

For non-native speakers, language was an important barrier for having a discussion with care providers.

\begin{tabular}{|c|c|c|c|}
\hline $\begin{array}{l}\text { Patients were often poorly informed about disease progression and treatment } \\
\text { options. }\end{array}$ & CKD, ESKD & LMIC, HIC & ++ \\
\hline $\begin{array}{l}\text { Patients and carers had to identify institutions to obtain diagnosis, laboratory } \\
\text { results and treatment. }\end{array}$ & CKD, ESKD & LMIC & ++ \\
\hline $\begin{array}{l}\text { Homelessness, unsuitable housing, lack of utilities, critical to self-care and } \\
\text { home dialysis. }\end{array}$ & ESKD & HIC, LMIC & ++ \\
\hline $\begin{array}{l}\text { Loss of employment may lead to uninsurance or underinsurance limiting or } \\
\text { preventing access to treatment. }\end{array}$ & ESKD & HIC, LMIC & +++ \\
\hline
\end{tabular}

Complex medication regimens were managed through dispensing aids, associated activities, family support.

\begin{tabular}{lll}
$\begin{array}{l}\text { Group of patient } \\
\text { mostly affected }\end{array}$ & $\begin{array}{l}\text { Type of country } \\
\text { mostly affected }\end{array}$ & Severity \\
\hline CKD, ESKD & LMIC & +++ \\
ESKD & LMIC & +++ \\
\hline
\end{tabular}

$\begin{array}{lll}\text { CKD , ESKD } & \text { LMIC } & +++ \\ \text { CKD, ESKD } & \text { HIC } & ++\end{array}$

ESKD $\quad$ LMIC $\quad+++$

When taking care of their vascular access, patients made efforts to protect the ESKD

CKD, ESKD

HIC, LMIC

$+$ arm.

\begin{tabular}{|c|c|c|c|}
\hline $\begin{array}{l}\text { Patients controlled diets and fluid intake, modified social activities to minimise } \\
\text { exposure and pressure. }\end{array}$ & CKD, ESKD & HIC, LMIC & ++ \\
\hline $\begin{array}{l}\text { Patients often travelled for long distances to dialysis centres, three times a } \\
\text { week. }\end{array}$ & ESKD & HIC, LMIC & ++ \\
\hline $\begin{array}{l}\text { Home dialysis patients had to pay transport to training, appointments and } \\
\text { other check-ups. }\end{array}$ & ESKD & HIC, LMIC & ++ \\
\hline Patients arranged daily activities between sessions. & ESKD & HIC, LMIC & + \\
\hline For home dialysis, training was required with extended periods off work. & ESKD & HIC, LMIC & + \\
\hline For home dialysis, homes needed physical adaptation. & ESKD & HIC, LMIC & + \\
\hline $\begin{array}{l}\text { For home dialysis, tasks were managing treatment, monitoring, titrating } \\
\text { medications, adopting aseptic techniques. }\end{array}$ & ESKD & HIC, LMIC & ++ \\
\hline $\begin{array}{l}\text { Pretransplantation, specific adjustment tasks included: hospital visits, tests } \\
\text { and organising payment for treatment. }\end{array}$ & ESKD & HIC, LMIC & \\
\hline $\begin{array}{l}\text { Some people needed to negotiate donation of a kidney by living relatives or } \\
\text { others. }\end{array}$ & ESKD & HIC, LMIC & ++ \\
\hline Transplanted patients managed complex medication regimens. & ESKD & HIC, LMIC & + \\
\hline $\begin{array}{l}\text { Transplanted patients needed to manage relationships, finances and family } \\
\text { responsibilities. }\end{array}$ & ESKD & HIC, LMIC & ++ \\
\hline $\begin{array}{l}\text { Symptoms associated with dialysis limited daily activities, sometimes } \\
\text { overlooked by healthcare professionals. }\end{array}$ & ESKD & $\mathrm{HIC}$, LMIC & ++ \\
\hline $\begin{array}{l}\text { When in poor health, wider networks were necessary for daily activities, } \\
\text { transportation, symptom management. }\end{array}$ & ESKD & HIC, LMIC & ++ \\
\hline $\begin{array}{l}\text { Information on disease and treatment was often insufficient or difficult to } \\
\text { comprehend. }\end{array}$ & ESKD & HIC, LMIC & ++ \\
\hline Information about immunosuppression was hard to obtain. & ESKD & HIC, LMIC & ++ \\
\hline Lack of social support was a frequently reported problem. & ESKD & HIC, LMIC & ++ \\
\hline
\end{tabular}




\section{Challenge}

\begin{tabular}{llll}
$\begin{array}{l}\text { Many clinicians failed to discuss care, eligibility for transplant and potential } \\
\text { donors. }\end{array}$ & CKD, ESKD & HIC, LMIC & ++ \\
$\begin{array}{l}\text { Carers needed more information on dialysis techniques to feel confident. } \\
\begin{array}{l}\text { Patients and carers emphasised self-determination, autonomy and dignity } \\
\text { when nearing end of life. }\end{array}\end{array}$ & ESKD & HIC \\
\hline
\end{tabular}

Severity: + mild, ++ moderate, +++ very severe.

CKD, chronic kidney disease; ESKD, end-stage kidney disease; HIC, high-income country; LMIC, low-income and middleincome country.

patients because of pick-up delays, long distances or high costs. ${ }^{15}$ 47-49 537686 126-133 Patients receiving dialysis arranged their daily activities between treatment sessions, adjusted the timing and intensity of their activities to their fatigue and tried to schedule medical appointments all on oneday to avoid further interactions with the healthcare system. ${ }^{55} 134-145$ The treatment was seen by most patients as an emotional and time imposition that caused boredom and frustration. ${ }^{63}$ 146-152 Time was often spent waiting for visits, prescriptions and tests. ${ }^{55} 134-145153$ Parents also arranged child care while they were in sessions, or had to travel for treatment. ${ }^{495355154155}$

\section{Home dialysis}

For patients receiving home dialysis, training was required which necessitated extended periods of leave from work. ${ }^{61} 70$ 156-158 They and their families had to adapt their home to accommodate equipment and materials, and spent more time cleaning in case healthcare workers assessed their housing conditions. ${ }^{152}$ 158-162 Tasks associated included managing treatment at set times each day, recording blood pressure and body weight, titrating medications and adopting aseptic techniques, as well as adhering to diet and fluid restrictions. ${ }^{156157163}$ In the case of developing peritonitis, workload increased as antibiotics had to be reconstituted and injected. ${ }^{156157}$

\section{Pretransplantation adaptation}

People with ESKD adjusted to being on the transplant waiting list and prepared for the possibility of receiving a kidney from a deceased donor at any time. ${ }^{43} 115133$ 164-170 The tasks included hospital visits, several investigations and tests, saving money for the operation and maintaining robust health; many potential recipients felt overwhelmed by all that was necessary. ${ }^{132} 133164165$ 170-173 Talking to others about their requirement for a kidney transplant involved making the request itself to potential living donors, educating people about CKD, treatment options and donation. 3947164174

\section{Post-transplantation adjustment}

After transplantation, patients' workload included financial and occupational changes resulting from a new type of treatment and status, managing complex medication regimens and managing social relations. ${ }^{84} 85$ 175-180 These tasks had to be balanced against the work of safeguarding access to healthcare, organising their disability insurance, interacting with healthcare providers, managing symptoms, monitoring medication side effects and managing self-care in relation to diet, fluid and physical activity. ${ }^{84} 85$ 175-180 Although transplantation was seen as a route back to normality, it was laden with ambiguous feelings towards the donor, unanticipated challenges in forming or maintaining relationships, financial worries, the responsibility of supporting their family, disappointments when side effects were noticed and a prevailing prognostic uncertainty. ${ }^{83} 85$ 175-177 181-186

\section{Navigating healthcare structures}

Very often, patients had to identify and call on the appropriate institutions to obtain a diagnosis, laboratory exams, treatment or coverage; contacting several public and private healthcare providers, social insurance offices, charity organisations and non-governmental organisations. $^{48} 49125161$ In settings with coverage of RRT, socioeconomically disadvantaged patients could also find it difficult to access financial support and navigate the social support system, which resulted in not receiving the assistance to which they were entitled. ${ }^{51}$ Lack of continuity of care contributed to patients using services without sufficient expertise in CKD or ESKD, such as emergency departments or peripheral health centres. ${ }^{49} 101$ The efficiency focus of the medical system was perceived by patients and professionals as a barrier to a personal connection; moreover, patients also recognised professionals' dismissive attitudes towards patients' experiential knowledge. ${ }^{102} 173$

\section{Negotiating costs and fund-raising}

Those patients and carers in countries with limited health coverage needed to perform additional work; poor families sold goods, products or services, organised raffles to collect money or obtained loans. ${ }^{47-49} 125$ They also contacted treatment centres, other patients, hospitals and non-government organisations to ask for free dialysis sessions or medication. For this reason, disadvantaged people were advised by healthcare staff on how to seek help in charities and advocacy organisations. ${ }^{47}$ In more 
affluent settings, patients also struggled to negotiate coverage of extra expenses, such as those related to home dialysis or conservative management. ${ }^{5161}$

\section{Capacity}

Physical and mental capacity

The ability of people with ESKD to carry out daily activities, including their paid job, was limited by symptoms associated with the disease and dialysis treatment, such as pain, fatigue, anxiety, depression and sexual problems, ${ }^{3744} 55639096138140154187-201$ sometimes overlooked by healthcare professionals. ${ }^{58} 94101202-204$ When in poor physical health, patients relied on wider family networks and neighbours to help with activities related to BoT such as scheduling and attending medical appointments, arranging transportation to those appointments, ordering and arranging medical supplies and training; also, other daily tasks such as food preparation, or shopping. ${ }^{37118161205-209}$ Carers were involved in the dialysis procedure, accompanying patients to dialysis and responding to psychosocial needs. ${ }^{45} 6997129141143161$ 210-216 Patients' capacity to carry out the activities related to healthcare were affected by insufficient financial resources and the fear of catastrophic consequences, such as death because of lack of dialysis treatment or immunosuppressive medication in the case of transplanted patients. ${ }^{4} 4952217218$

\section{Managing information}

Obtaining information on the disease and treatment was a significant burden for patients and carers. Patients reported that their information on the disease and treatment options was often insufficient or difficult to comprehend, particularly during the early stages of their trajectory, independent of income or coverage level. ${ }^{38} 5057586163647792109121125$ 127-131 188 205 219-230 Patients may not have asked for clarification for fear of not understanding or because they did not even know what to ask; the desire for more patient-centred care were widely expressed. Short clinic visits, unknown technical jargon and high levels of anxiety were barriers to accessing information. 61102223 231-234 Other patients could sometimes supply information about dialysis options, travelling, hygiene regimens, dietary restrictions, benefit advice, timing of treatment and pain management. ${ }^{117} 174$ 235-238 For organ donation and transplantation, people usually received information through discussions with other patients, providers, social workers, financial representatives, the internet and, in affluent populations, informative meetings. ${ }^{117} 174235-238$ In relation to transplantation, patients reported they needed practical information about the unexpected side effects of immunosuppressive medication; most frequently mentioned were higher risk of cancer, infections, weight gain and fragile skin. ${ }^{178} 184185$ 239-242 Other information needs for transplanted patients included coping with emotions related to the transplant, what to do when a suitable organ became available, alternatives to transplantation and how the waiting list worked. ${ }^{240} 242-245$ Family members were afraid to bother the healthcare team, ${ }^{246}$ and perceiving little power in comparison to healthcare professionals, downplayed their knowledge in front of them. ${ }^{210}$ Patients and carers were responsible for obtaining and carrying their medical files and test results to appointments when the healthcare administrative systems were not integrated. ${ }^{49} 125$ Some had anticipated that transplantation would offer dramatic health improvement but were disappointed when they experienced side effects, particularly cancer. $^{4463101106122167190193199206214 \text { 247-251 }}$

\section{Social support}

Most people highlighted the support from family, neighbours, friends, staff, other patients and church communities; friends, staff and spiritual groups were particularly important for those living alone. ${ }^{99446062} 215247249$ 252-258 A lack of social support was also frequently reported. ${ }^{44} 60247259$ In a UK study, patients' socioeconomic disadvantage adversely affected the availability of social support, and it was suggested that personal relationships sometimes broke down when potential donors declined to donate. ${ }^{39}$ Attending dialysis was sometimes seen as a social outlet, where they could make friends with staff and patients. Younger participants often considered the schedule flexibility of home dialysis as an opportunity for maintaining their employment and contact with their family and established social networks. ${ }^{61} 152$ To demonstrate resilience, some patients tried to maintain a sense of normalcy, integrating the dialysis community into their social network. ${ }^{42} 139210260$

\section{Experienced control}

\section{Personal control}

Feelings of personal control were achieved through learning how to manage CKD and ESKD, finding a balance between illness and normalcy, or even denying the seriousness of their condition. ${ }^{218260}{ }^{261}$ The experience of feelings of personal control led to increased self-confidence and well-being. ${ }^{15} 189251$ Strategies for maintaining control included requesting tests, withholding information from clinicians, monitoring and modifying their treatments and checking the activities of dialysis nurses assisting them. ${ }^{139} 246251$ 262-265 People with ESKD experimented with their therapy to determine if the prescriptions were really necessary, they also shortened dialysis hours to reduce worsening symptoms, to meet work commitments, or to participate in an unexpected social situation. ${ }^{54} 55$ Lengthening treatment hours could facilitate higher than usual fluid removal or managing symptoms. ${ }^{545}$ Some patients entrusted decisions entirely to the care team, and this promoted feelings of security. ${ }^{61} 70102107266267$ The main barrier to personal control was lack of information about treatments, test results and the course of their illness and that they could not choose when and where to travel. ${ }^{15} 436163197239268$ However, even when patients knew they were not in control, they felt unsafe if the treatment went differently from what was expected. ${ }^{269}$ Patients recognised prognostic uncertainty, and their own fear of 
incompetence as an obstacle to choosing the appropriate

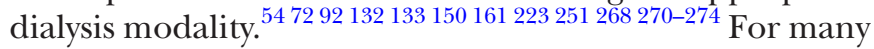
patients, home dialysis restored a sense of control and freedom to manage their schedule, especially if it was

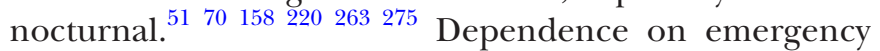
care or on fund-raising tasks to cover life-saving treatment represented a severe case of lack of experienced control. $^{35} 47-495266$

\section{Control and decision-making}

Control translated into participation in decision-making, which was affected by the healthcare staff's attitude towards the patients' adherence to treatment. ${ }^{236}$ Lack of choice in decision-making about dialysis modality was very common; when possible, modality was negotiated and agreed after discussions with clinicians and family members, reading educational material or attending informational meetings. 202248270273274 276-278 Home dialysis patients appreciated training to build confidence and skills to use the machine. ${ }^{5470111270279280}$ Patients in dialysis aspired to improve their situation by receiving a transplant, motivating them to adhere to treatment; other motivations included family, especially their children, work and beliefs. ${ }^{55} 58281$ People with ESKD whose clinicians failed to discuss care, eligibility and ineligibility for transplant, and potential donors with them felt disempowered. ${ }^{39} 5557587778169282$ When relatives offered to donate a kidney, many patients felt reluctant to accept this because of their concerns about the future health of the donor; other patients had reservations about accepting kidneys from deceased donors because of the donor's age and medical history. ${ }^{172} 181235$ Once transplanted, the main clinical objective was preserving the graft. However, the disease and its treatment continued to be a significant burden on patients' social capital and financial capacity, with unexpected side effects. ${ }^{496389} 96167283-285$

\section{Carers involvement}

Relatives wanted to be involved in discussions on dialysis modality as dialysis would take up a large part of their lives. 5570111 156-158223 279286 Carers of patients on home dialysis needed to know more about the dialysis techniques to feel confident about self-managing the treatment, they stressed the importance of 24 hours telephone access for advice. ${ }^{6169}$ Family members were afraid to bother the healthcare team, ${ }^{246}$ and perceiving little power in comparison to healthcare professionals, used strategies to downplay their knowledge of the disease or the treatment in front of them. ${ }^{210} 287$ To cope with caring, carers sought support in psychiatric help or religion when available, or support in religion. ${ }^{141247}$ Patients who decided to stop dialysis did not usually ask for their carers' opinion; when physicians thought the patient was too ill to decide, carers were consulted and felt death could be liberating if the patient was in pain and with no response to treatment. $^{134141161}$

\section{End-of-life decisions}

Some patients felt that advance care planning (ACP) was hard and unnecessary as they trusted their families to make decisions; others were less concerned, trusted their healthcare team and felt empowered. ${ }^{236288} 289$ Family members felt ACP was necessary as a means to protect patients. ${ }^{290-292}$ At the end of life, maintaining control was a struggle with respect to autonomy and dignity. ${ }^{134136205251}$ Patients based their dialysis withdrawal or non-acceptance decision on having lived a full life, on nature taking its course, on their fear of being a burden for their families, their bodies being invaded and dialysis accelerating death. ${ }^{128} 293$ For some, the decision to withdraw from dialysis meant asserting their self-determination. ${ }^{251294}$ Carers' acceptance of patients' decision was influenced by the perception of conservative management as a non-invasive treatment, the advanced age of the patient and the lack of benefit received from haemodialysis. ${ }^{64128134161}$ Although family members were often uncomfortable about making end-of-life decisions, they tended to recognise it was important to respect the patient's wishes. ${ }^{202} 233292$ Figure 2 shows thematic schema of experienced control and cognitive authority in CKD.

\section{DISCUSSION}

Our findings demonstrate that the work and capacity of patients and carers are highly unstable situational factors that make up the BoT. Capacity is particularly diminished by socioeconomic factors, which ultimately exacerbates the work of patients and their carers; this may occur even in regions with universal health coverage. Particularly in LMICs, patients with ESKD are often underinsured or not at all, which makes it almost impossible for them to attain life-saving treatments. Patients with ESKD can be caught in a vicious cycle, whereby they lose their job and health insurance because of ill health or because they need time off from work to attend dialysis, leading to exacerbations in disease, lack of financial access to treatment and difficulty obtaining a job because of poor health. Patients often fear catastrophic consequences due to a lack of financial capacity, and make strenuous efforts to prevent them. Thematic syntheses with robust methods have covered different aspects of being a patient with CKD. ${ }^{295-308}$ Here, we focused on three elements of BoT, namely workload, capacity and experienced control, to develop an understanding of the BoT of CKD, focusing on ESKD and including the experiences of patients in contexts of structural inequalities.

Worldwide, many individuals with CKD and especially with ESKD receive no treatment or receive only fragmented care. ${ }^{8} 35$ 309-314 Millions of preventable deaths occur because of lack of access to RRT. ${ }^{9}$ Moreover, in some LMICs with universal health coverage, resources may be limited because of geography or poor infrastructure; in such cases, the use of free health providers can create delays that compromise the treatment itself, resulting in patients struggling to pay for private providers. When 


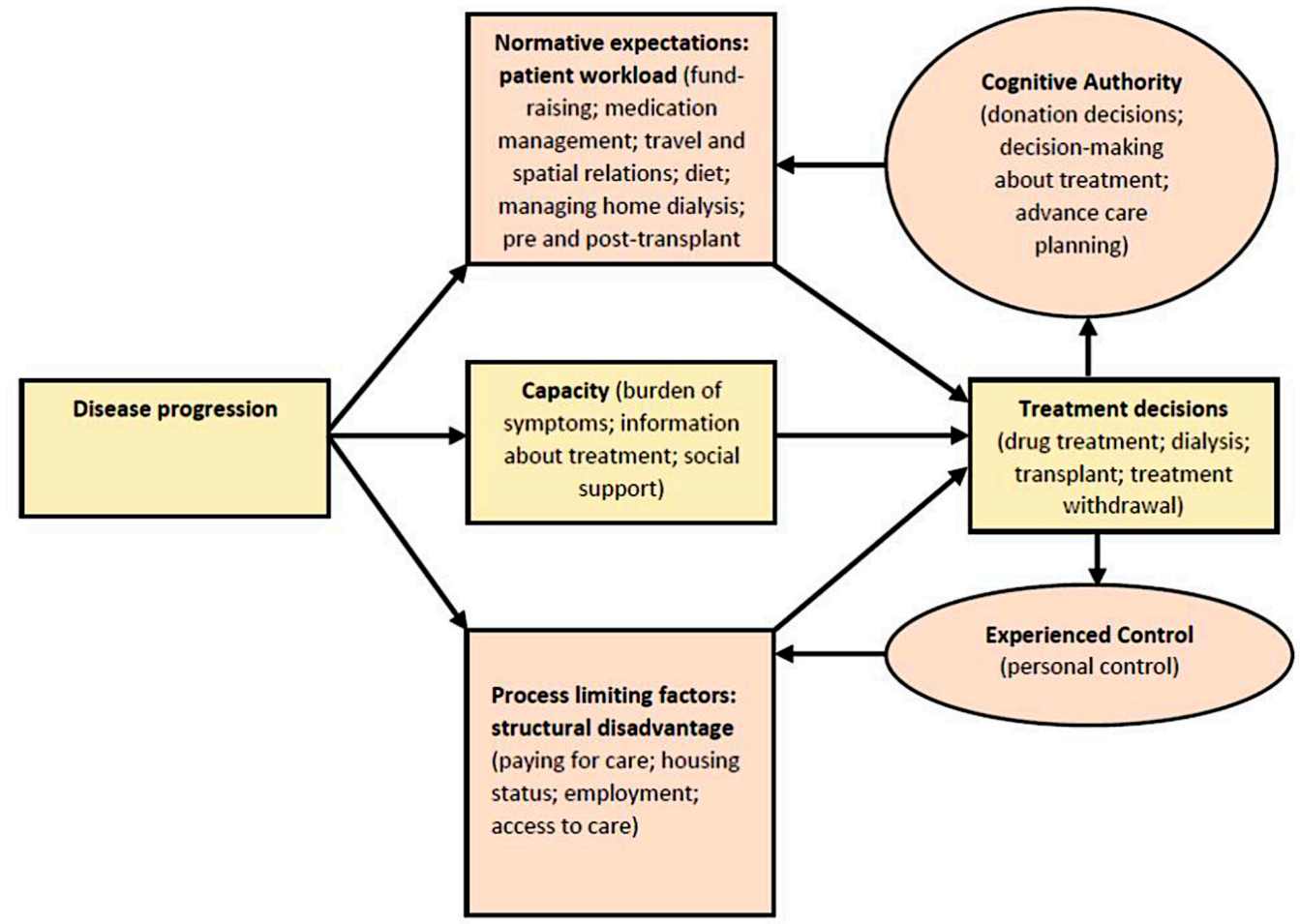

Figure 2 Thematic schema of experienced control and cognitive authority in chronic kidney disease.

this occurs, healthcare becomes fragmented and uncoordinated. Even in some modern welfare states, health inequalities persist, particularly affecting minorities, those who are unemployed or undocumented. ${ }^{315}$ One example is the use of emergency haemodialysis by undocumented and uninsured immigrants with ESKD.$^{52}$ Several studies have highlighted the imperative necessity to address this disturbing reality. ${ }^{316-323}$

When health systems fail to meet patients' treatment needs, patients mobilise resources and develop coping strategies such as accepting charity or selling assets. ${ }^{1329} 312$ This distressing scenario adds to their workload and very easily overwhelms patients' capacity. Transportation to and from dialysis centres is a frequent challenge, it is time-consuming, costly or simply not available. Those patients living in non-urban areas in countries where home dialysis is not available have to travel long distances or relocate to access treatment; some may be faced with the decision of leaving their young children in the care of others for long periods of time. In many LMICs, the costs of RRT remain prohibited for both individuals and healthcare systems; dialysis and transplantation costs often lead to financial ruin of the family, discontinuation and death. ${ }^{324}$ In fact, patients, families and healthcare professionals are burdened with having to choose between life and death. ${ }^{324}$ On the other hand, in countries with robust health coverage, patients may feel overwhelmed even by having to travel short distances to the treatment centre every 2 days, especially if they do not have support or, if offered home dialysis, they may experience social isolation, unexpected costs and lack of sufficient technical assistance. In settings in which RRT costs are covered, patients may have the choice of not initiating or withdrawing from dialysis. ${ }^{324}$ Among other factors, advanced age, white ethnicity and chronic disease are associated with dialysis withdrawal. ${ }^{325}$

Support from social networks, professionals and other patients is critical in improving patient's capacity. Spirituality and church communities are significant resources for coping with illness and its treatment, as seen in several studies. ${ }^{21} 201249257$ 326-329 However, social support is not guaranteed; in some cultures, patients perceive lack of support by their own networks caused by discrimination because of their illness, leading to intolerable levels of BoT. ${ }^{446} 247259$ It has also been shown that informal care offered by family, friends or neighbours can burden patients through uncomfortable feelings of dependency or the obligation to have an optimistic attitude towards their condition. ${ }^{330}$ Our findings support this view; patients often fear becoming a burden on their families, which affects their decisions related to treatment options.

We confirmed that patients' capacity can be undermined by insufficient or inadequate information. Deficits in communication between patients and professionals are endemic and rooted in structural and system factors. ${ }^{20} 30296308331$ This shortfall affects decisions regarding dialysis modality, medication management and the possibility of using a living donation. Patient discussions with professionals must result in a collaborative partnership and should not simply provide information. ${ }^{330}$ For example, patients' concerns and expectations about waitlists, eligibility and allocation for transplantation could be addressed via additional information, 
clinical conversations and access to specialised psychological therapists. ${ }^{306}$

Immigrant populations do not always have access to healthcare; when they do, language, cultural and religious differences can act as barriers to care and contribute to the BoT. In high-income countries, the need to provide RRT for migrants and refugees with ESKD will increase as more people are displaced to countries where RRT is available; this situation poses ethical challenges at the societal and individual levels. ${ }^{321}$ It is necessary to promote and support equitable access to care for those living within any border by means of organisational position statements and focused research. ${ }^{322}$ For migrants with access to care, culturally competent navigator programmes could contribute to the improvement of healthcare disparities. ${ }^{332}$

Surprisingly, patients who undergo haemodialysis tend to perceive that staff underestimate their capacities. ${ }^{58} 94101{ }^{202-204}$ When healthcare professionals do not take into consideration patients' knowledge or values, a diminished participation in self-care and relationally induced non-adherence can occur. Treatment plans should be discussed against an assessment of patient and caregiver capacity, as well as their material, social and cognitive resources. ${ }^{28} 333$

Changes in treatment may be needed as CKD progresses to its later stages-symptom control may become the main treatment focus. ${ }^{1011}$ Our results relate predominantly to the BoT of patients with ESKD, as most reports included in this systematic review have addressed the experiences of this group of patients. Indeed, a large proportion of patients with early stage CKD are unaware of their diagnosis. ${ }^{334}$ In patients whose kidney function will not decline to a point necessitating RRT, the overall BoT may be related to a reduction of risk. ${ }^{10}{ }^{11}$ In the later stages of CKD, symptom control may become the main treatment focus, and the time-consuming and invasive treatment of dialysis, by any modality, and all tasks related to dialysis represent considerable portions of the burden. ${ }^{10} 11$ Moreover, the BoT is influenced by patients' financial resources, family support and comorbidities, as well as the healthcare setting. In fact, because of the likely coexistence of multiple conditions, elderly patients experience a greater BoT than do younger patients. ${ }^{24}$ Management should be coordinated among professionals, particularly for patients with ESKD and multiple morbidities, ${ }^{23}$ who frequently experience fragmented care with a substantial time and travel burden, as well as contradictory healthcare advice. $^{23}$

Challenged by constraints, a patient's sense of control can become fragile. As seen in our review, patients often employ a range of strategies to retain their control, such as withholding clinical information from professionals, asking for additional tests or modifying their treatment. Although a patient's capacity to cope with BoT is often exceeded, healthcare systems increasingly delegate responsibilities to patients and carers, focusing on self-management and compliance. ${ }^{30}$ 335 When overwhelmed, patients may be forced to renegotiate their responsibilities with actors in the health system and their own social networks. ${ }^{29}$

Our review has important limitations. The variety of methodologies, quality of reporting and heterogeneity of perspectives make synthesis difficult. Only studies that included face-to-face interviews were included to capture rich qualitative data, and studies that reported methods such as telephone and postal questionnaires or surveys were excluded. Studies with paediatric patients and/or their carers were excluded, as BoT may significantly differ. Although the use of framework analysis can improve the transparency of coding and identify underlying assumptions, it can also be interpreted as a limitation because findings may be influenced by and connected to these theories. For a more global perspective, studies published in other languages could have been included. Grey literature was excluded to manage the scope of the review. We analysed data with a coding framework supported by middle-range theories to understand the work involved in being a person with CKD and how practises are organised and integrated into social contexts. The major strengths of this study are the comprehensive inclusion of publications in the English, Spanish and Portuguese languages to understand the experience of patients in LMICs, which may enhance the transferability of our findings, the broad description of BoT across all stages of CKD and the use of theories to underpin our findings. However, the included studies representing only some LMICs can hardly be presumed to reflect patients' experiences in these countries.

\section{CONCLUSION}

To the best of our knowledge, this is the first theory-led review that focuses on the structural inequalities that shape patients' and caregivers' experiences related to BoT in CKD. The inclusion of LMICs extends our understanding of the experiences of individuals living in these countries and the work they undertake to manage their conditions. CKD can result in invasive and exhausting BoT, which is exacerbated in contexts of limited health coverage, socioeconomic disadvantages and marked imbalances in power. An urgent, collaborative, multipronged approach is needed to address the overwhelming BoT of CKD that, in many populations, results in premature death. ${ }^{8}{ }^{312}$ However, knowledge gaps persist in resource-limited settings and the nephrology community need to quantify the burden of CKD, understand its social impact, raise awareness of the disease among healthcare workers and advocate for cost-effective and setting-specific detection and prevention strategies. ${ }^{9} 324336337$ The design of innovative policies, interventions and activities are warranted to support and empower patients, considering the constraints and structure of systems that patients navigate in their disease trajectory. This will lead to a better understand of their burden, with the objective of improving quality of care and the illness experience. 
Acknowledgements The authors would like to thank the systematic reviews group of the York Health Economics Consortium (YHEC) for developing the original search strategy.

Contributors JR drafted the paper. AC, MM, CRM and JH screened titles and abstracts in first search round. Full papers were screened by $\mathrm{JH}, \mathrm{KL}, \mathrm{MM}, \mathrm{KH}$ and AC. JR performed database searches for update and extension of search. JR, JPA and FC screened updated results. JR, CRM and JPA performed content analysis. CRM, MM, AC and JPA critically reviewed the manuscript for important intellectual content; all authors approved the final version of the paper.

Funding The first stages of this project (EXPERTS1 Protocol, search strategy and meta review) were partially funded by the National Institute for Health Research Collaboration for Leadership in Applied Health Research and Care (NIHR CLAHRC) Wessex, which is a partnership between Wessex NHS organisations and partners and the University of Southampton.

Disclaimer The views expressed are those of the author(s) and not necessarily those of the NHS, the NIHR or the Department of Health. Funders had no role in study design, data collection and analysis, decision to publish or preparation of the manuscript.

\section{Competing interests None declared.}

Patient consent Not required.

Provenance and peer review Not commissioned; externally peer reviewed.

Data sharing statement EXPERTS1 Protocol is published in BMJ Open, with open access CRM, Masters J, Welch L, Hunt K, Pope C, Myall M, Griffiths P, Roderick $P$, Glanville J, Richardson A: EXPERTS1 — experiences of long-term life-limiting conditions among patients and carers: protocol for a qualitative meta-synthesis and conceptual modelling study. BMJ Open 2015, 5(4):e007372. Meta-review of systematic reviews is published in BMJ Open, with open access CRM, Cummings A, Myall M, Harvey J, Pope C, Griffiths P, Roderick P, Arber M, Boehmer K, Mair FS et al: experiences of long-term life-limiting conditions among patients and carers: what can we learn from a meta-review of systematic reviews of qualitative studies of chronic heart failure, chronic obstructive pulmonary disease and chronic kidney disease? BMJ Open 2016, 6(10):e011694. Search strategy is included as supplementary file.

Open access This is an open access article distributed in accordance with the Creative Commons Attribution Non Commercial (CC BY-NC 4.0) license, which permits others to distribute, remix, adapt, build upon this work non-commercially, and license their derivative works on different terms, provided the original work is properly cited, appropriate credit is given, any changes made indicated, and the use is non-commercial. See: http://creativecommons.org/licenses/by-nc/4.0/.

\section{REFERENCES}

1. Ene-lordache B, Perico N, Bikbov B, et al. Chronic kidney disease and cardiovascular risk in six regions of the world (ISN-KDDC): a cross-sectional study. Lancet Glob Health 2016;4:e307-e319.

2. Schlieper G, Hess K, Floege J, et al. The vulnerable patient with chronic kidney disease. Nephrology Dialysis Transplantation 2016;31:382-90.

3. As G, Chertow GM, Fan D, et al. Chronic Kidney Disease and the Risks of Death, Cardiovascular Events, and Hospitalization. N Engl J Med 2016;351:1296-305.

4. Chillon JM, Massy ZA, Stengel B. Neurological complications in chronic kidney disease patients. Nephrol Dial Transplant 2016:31:1606-14.

5. Jhee JH, Lee E, Cha MU, et al. Prevalence of depression and suicidal ideation increases proportionally with renal function decline, beginning from early stages of chronic kidney disease. Medicine 2017;96:e8476.

6. Goh ZS, Griva K. Anxiety and depression in patients with end-stage renal disease: impact and management challenges - a narrative review. Int J Nephrol Renovasc Dis 2018;11:93-102.

7. Levin A, Tonelli M, Bonventre J, et al. Global kidney health 2017 and beyond: a roadmap for closing gaps in care, research, and policy. Lancet 2017:390:1888-917.

8. Stanifer JW, Muiru A, Jafar TH, et al. Chronic kidney disease in lowand middle-income countries. Nephrology Dialysis Transplantation 2016;31:868-74.

9. Liyanage T, Ninomiya T, Jha V, et al. Worldwide access to treatment for end-stage kidney disease: a systematic review. Lancet 2015;385:1975-82.
10. Fraser SD, Roderick PJ, May CR, et al. The burden of comorbidity in people with chronic kidney disease stage 3: a cohort study. BMC Nephrol 2015;16:193.

11. Fraser SD, Taal MW. Multimorbidity in people with chronic kidney disease: implications for outcomes and treatment. Curr Opin Nephrol Hypertens 2016;25:465-72.

12. Holman HR. Chronic disease and the healthcare crisis. Chronic IIIn 2005;1:265-74.

13. May CR, Eton DT, Boehmer K, et al. Rethinking the patient: using burden of treatment theory to understand the changing dynamics of illness. BMC Health Serv Res 2014;14:281.

14. May C. Chronic illness and intractability: professional-patient interactions in primary care. Chronic IIIn 2005;1:15-20.

15. Karamanidou C, Weinman J, Horne R. A qualitative study of treatment burden among haemodialysis recipients. J Health Psychol 2014;19:556-69.

16. Eton DT, Elraiyah TA, Yost KJ, et al. A systematic review of patientreported measures of burden of treatment in three chronic diseases. Patient Relat Outcome Meas 2013;4:7-20.

17. Bohlen K, Scoville E, Shippee ND, et al. Overwhelmed patients: a videographic analysis of how patients with type 2 diabetes and clinicians articulate and address treatment burden during clinical encounters. Diabetes Care 2012;35:47-9.

18. Gallacher K, Jani B, Morrison D, et al. Qualitative systematic reviews of treatment burden in stroke, heart failure and diabetes: methodological challenges and solutions. BMC Med Res Methodol 2013;13:10.

19. Gallacher K, May CR, Montori VM, et al. Understanding patients' experiences of treatment burden in chronic heart failure using normalization process theory. Ann Fam Med 2011;9:235-43.

20. Gallacher K, Morrison D, Jani B, et al. Uncovering treatment burden as a key concept for stroke care: a systematic review of qualitative research. PLoS Med 2013;10:e1001473.

21. Ridgeway JL, Egginton JS, Tiedje K, et al. Factors that lessen the burden of treatment in complex patients with chronic conditions: a qualitative study. Patient Prefer Adherence 2014;8:339-51.

22. Shippee ND, Shah ND, May CR, et al. Cumulative complexity: a functional, patient-centered model of patient complexity can improve research and practice. J Clin Epidemiol 2012;65:1041-51.

23. Sav A, Kendall E, McMillan SS, et al. 'You say treatment, I say hard work': treatment burden among people with chronic illness and their carers in Australia. Health Soc Care Community 2013;21:n/ a-74.

24. Sav A, King MA, Whitty JA, et al. Burden of treatment for chronic illness: a concept analysis and review of the literature. Health Expect 2015;18:312-24.

25. Eton DT, Ramalho de Oliveira D, Egginton JS, et al. Building a measurement framework of burden of treatment in complex patients with chronic conditions: a qualitative study. Patient Relat Outcome Meas 2012;3:39-49.

26. Eton DT, Ridgeway JL, Egginton JS, et al. Finalizing a measurement framework for the burden of treatment in complex patients with chronic conditions. Patient Relat Outcome Meas 2015;6:117-26.

27. Tran VT, Barnes C, Montori VM, et al. Taxonomy of the burden of treatment: a multi-country web-based qualitative study of patients with chronic conditions. BMC Med 2015;13:115.

28. Boehmer KR, Gionfriddo MR, Rodriguez-Gutierrez R, et al. Patient capacity and constraints in the experience of chronic disease: a qualitative systematic review and thematic synthesis. BMC Fam Pract 2016;17:127.

29. Hunt KJ, May CR. Managing expectations: cognitive authority and experienced control in complex healthcare processes. BMC Health Serv Res 2017;17:459.

30. May CR, Cummings A, Myall M, et al. Experiences of long-term lifelimiting conditions among patients and carers: what can we learn from a meta-review of systematic reviews of qualitative studies of chronic heart failure, chronic obstructive pulmonary disease and chronic kidney disease? BMJ Open 2016;6:e011694.

31. May CR, Masters J, Welch L, et al. EXPERTS 1-experiences of longterm life-limiting conditions among patients and carers: protocol for a qualitative meta-synthesis and conceptual modelling study. BMJ Open 2015;5:e007372.

32. Tong A, Flemming K, Mclnnes E, et al. Enhancing transparency in reporting the synthesis of qualitative research: ENTREQ. BMC Med Res Methodol 2012;12:181.

33. CASP Checklists. Critical Appraisal Skills Program (CASP). Oxford: CASP Checklists, 2014.

34. May C, Finch T. Implementing, Embedding, and Integrating Practices: an outline of normalization process theory. Sociology 2009;43:535-54. 
35. Kahn LS, Vest BM, Madurai N, et al. Chronic kidney disease (CKD) treatment burden among low-income primary care patients. Chronic IIIn 2015;11:171-83.

36. Demain S, Gonçalves AC, Areia C, et al. Living with, managing and minimising treatment burden in long term conditions: a systematic review of qualitative research. PLoS One 2015;10:e0125457.

37. Fráguas G, Soares SM, Silva PA. The Family in the Context of the Care to the Diabetic Nephropathy-holder: demands and resources. Escola Anna Nery - Revista de Enfermagem 2008;12:271-7.

38. Ashby M, op't Hoog C, Kellehear A, et al. Renal dialysis abatement: lessons from a social study. Palliat Med 2005;19:389-96.

39. Bailey PK, Ben-Shlomo Y, Tomson CR, et al. Socioeconomic deprivation and barriers to live-donor kidney transplantation: a qualitative study of deceased-donor kidney transplant recipients. BMJ Open 2016;6:e010605.

40. Chiaranai $\mathrm{C}$. The lived experience of patients receiving hemodialysis treatment for end-stage renal disease: a qualitative study. J Nurs Res 2016;24:101-8.

41. Cho MK, Shin G. Gender-based experiences on the survival of chronic renal failure patients under hemodialysis for more than 20 years. Appl Nurs Res 2016;32:262-8.

42. Dekker W, Uerz I, Wils JP. Living well with end stage renal disease: patients' narratives interrupted from a virtue perspective. Ethical Theory Moral Pract 2005;8:485-506.

43. Ekelund ML, Andersson SI. "I need to lead my own life in any case"-a study of patients in dialysis with or without a partner. Patient Educ Couns 2010;81:30-6.

44. Kazley AS, Johnson E, Simpson K, et al. African American patient knowledge of kidney disease: a qualitative study of those with advanced chronic kidney disease. Chronic IIIn 2015;11:245-55.

45. Lee VY, Seah WY, Kang AW, et al. Managing multiple chronic conditions in Singapore - Exploring the perspectives and experiences of family caregivers of patients with diabetes and end stage renal disease on haemodialysis. Psychol Health 2016;31:1220-36

46. Lindberg M, Lindberg P. Overcoming obstacles for adherence to phosphate binding medication in dialysis patients: a qualitative study. Pharm World Sci 2008;30:571-6.

47. Mercado-Martínez FJ, Correa-Mauricio ME. [Living in hemodialysis without social insurance: the voices of renal sick people and their families]. Salud Publica Mex 2015;57:155-60.

48. Mercado-Martinez FJ, Silva DGVda, Souza SdaSde, et al. Vivendo com insuficiência renal: obstáculos na terapia da hemodiálise na perspectiva das pessoas doentes e suas famílias. Physis: Revista de Saúde Coletiva 2015;25:59-74.

49. Mercado-Martínez FJ, Hernández-Ibarra E, Ascencio-Mera CD, et al. Viviendo con trasplante renal, sin protección social en salud: ¿Qué dicen los enfermos sobre las dificultades económicas que enfrentan y sus efectos? Cadernos de Saúde Pública 2014;30:2092-100.

50. Seah AS, Tan F, Srinivas S, et al. Opting out of dialysis - Exploring patients' decisions to forego dialysis in favour of conservative nondialytic management for end-stage renal disease. Health Expect 2015; 18:1018-29.

51. Walker RC, Howard K, Tong A, et al. The economic considerations of patients and caregivers in choice of dialysis modality. Hemodial Int 2016;20:634-42.

52. Cervantes L, Fischer S, Berlinger N, et al. THe illness experience of undocumented immigrants with end-stage renal disease. JAMA Intern Med 2017;177:529-35.

53. Anderson $\mathrm{K}$, Cunningham J, Devitt J, et al. "Looking back to my family": indigenous Australian patients' experience of hemodialysis. BMC Nephrol 2012;13:114.

54. Polaschek N. Living on dialysis: concerns of clients in a renal setting. J Adv Nurs 2003;41:44-52.

55. Polaschek N. Managing home dialysis: the client perspective on independent treatment. Renal Society of Australasia Journal 2006;2:53-63.

56. Polaschek N. 'Doing dialysis at home': client attitudes towards renal therapy. J Clin Nurs 2007;16(3A):51-8.

57. Rix EF, Barclay L, Stirling J, et al. The perspectives of Aboriginal patients and their health care providers on improving the quality of hemodialysis services: a qualitative study. Hemodial Int 2015;19:80-9.

58. Rix EF, Barclay L, Stirling J, et al. 'Beats the alternative but it messes up your life': aboriginal people's experience of haemodialysis in rural Australia. BMJ Open 2014;4:e005945

59. Shih LC, Honey M. The impact of dialysis on rurally based Māori and their whānau/families. Nurs Prax N Z 2011;27:5-15.

60. Valsaraj BP, Bhat SM, Prabhu R, et al. A qualitative research on the experience of haemodialysis in South Karnataka: lived experience of persons undergoing haemodialysis. Journal of Krishna Institute of Medical Sciences University 2014;3:90-100.

61. Walker RC, Howard K, Morton RL, et al. Patient and caregiver values, beliefs and experiences when considering home dialysis as a treatment option: a semi-structured interview study. Nephrol Dial Transplant 2016;31:133-41.

62. Wells SA. Determinants of adherence to living on dialysis for Mexican Americans. Sage Open 2015;5:215824401557496-12.

63. Tong A, Sainsbury P, Chadban S, et al. Patients' experiences and perspectives of living with CKD. Am J Kidney Dis 2009;53:689-700.

64. Allen D, Badro V, Denyer-Willis L, et al. Fragmented care and wholeperson illness: Decision-making for people with chronic end-stage kidney disease. Chronic IIIn 2015;11:44-55.

65. Oyegbile YO, Brysiewicz P. Family caregiver's experiences of providing care to patients with End-Stage Renal Disease in SouthWest Nigeria. J Clin Nurs 2017;26(17-18):2624-32.

66. Wu CC, Lin CC, Hsieh HF, et al. Lived experiences and illness representation of Taiwanese patients with late-stage chronic kidney disease. J Health Psychol 2016;21:2788-98.

67. Nobahar M. Exploring experiences of the quality of nursing care among patients, nurses, caregivers and physicians in a haemodialysis department. Journal of Renal Care 2016;xx(xx):1-10.

68. Nobahar M, Tamadon MR. Barriers to and facilitators of care for hemodialysis patients; a qualitative study. J Renal Inj Prev 2016;5:39-44

69. Blogg $\mathrm{AH}$, Hyde $\mathrm{C}$. The experience of spouses caring for a person on home haemodialysis: an ethnography. Renal Society of Australasia Journal 2008;4:75-80.

70. Hanson CS, Chapman JR, Craig JC, et al. Patient experiences of training and transition to home haemodialysis: a mixed-methods study. Nephrology 2017;22:631-41.

71. Rygh E, Arild E, Johnsen E, et al. Choosing to live with home dialysis-patients' experiences and potential for telemedicine support: a qualitative study. BMC Nephrol 2012;13:13(13):13.

72. MLcAj S, GAdS B, Pereira ER, et al. Patients' experiences of peritoneal dialysis at home: a phenomenological approach. Rev Latino-am Enfermagem 2012;20:68-75.

73. Keeping LM, English LM. Informal and incidental learning with patients who use continuous ambulatory peritoneal dialysis. Nephrol Nurs J 2001;28:313-23.

74. Wilkinson E, Randhawa G, Brown E, et al. Exploring access to end of life care for ethnic minorities with end stage kidney disease through recruitment in action research. BMC Palliat Care 2016;15:57.

75. Wilkinson E, Randhawa G, Farrington K, et al. Lack of awareness of kidney complications despite familiarity with diabetes: a multiethnic qualitative study. J Ren Care 2011;37:2-11.

76. Tijerina MS. Psychosocial factors influencing Mexican-American women's adherence with hemodialysis treatment. Soc Work Health Care 2006;43:57-74

77. Anderson K, Devitt J, Cunningham J, et al. "All they said was my kidneys were dead": Indigenous Australian patients understanding of their chronic kidney disease. Med J Aust 2008; 189:499-503.

78. Burnette L, Kickett M. 'You are just a puppet': Australian Aboriginal people's experience of disempowerment when undergoing treatment for end-stage renal disease. Renal Society of Australasia Journal 2009;5:113-8.

79. Morton RL, Devitt J, Howard K, et al. Patient views about treatment of stage 5 CKD: a qualitative analysis of semistructured interviews. Am J Kidney Dis 2010;55:431-40.

80. Walker RC, Walker S, Morton RL, et al. Māori patients' experiences and perspectives of chronic kidney disease: a New Zealand qualitative interview study. BMJ Open 2017;7:e013829.

81. Stewart M. Qualitative inquiry: perceptions of sexuality by African Americans experiencing haemodialysis. $J$ Adv Nurs 2013;69:1704-13

82. Salvalaggio GK, L.: Minore B. Perspectives on health: experiences of First Nations dialysis patients relocated from remote communities for treatment. Canadian Journal of Rural Medicine 2003:8:19-24.

83. Crowley-Matoka M. Desperately seeking "normal": the promise and perils of living with kidney transplantation. Soc Sci Med 2005;61:821-31.

84. Gordon EJ, Prohaska TR, Gallant M, et al. Self-care strategies and barriers among kidney transplant recipients: a qualitative study. Chronic IIIn 2009;5:75-91.

85. Schmid-Mohler G, Schäfer-Keller P, Frei A, et al. A mixed-method study to explore patients' perspective of self-management tasks in the early phase after kidney transplant. Prog Transplant 2014;24:8-18. 
86. Chenitz KB, Fernando M, Shea JA. In-center hemodialysis attendance: patient perceptions of risks, barriers, and recommendations. Hemodial Int 2014;18:364-73.

87. Campos CJ, Turato ER. [Hemodialysis treatment as perceived by the renal patient: clinical qualitative study]. Rev Bras Enferm 2010;63:799-805.

88. Campos CG, Mantovani MF, Nascimento ME, et al. [Social representations of illness among people with chronic kidney disease]. Rev Gaucha Enferm 2015;36:106-12.

89. de Brito DC, de Paula AM, Grincenkov FR, et al. Analysis of the changes and difficulties arising from kidney transplantation: a qualitative study. Rev Lat Am Enfermagem 2015;23:419-26.

90. Finnegan-John J, Thomas VJ. The psychosocial experience of patients with end-stage renal disease and its impact on quality of life: findings from a needs assessment to shape a service. ISRN Nephrol 2013;2013:1-8.

91. King N, Carroll C, Newton P, et al. "You can't cure it so you have to endure it": the experience of adaptation to diabetic renal disease. Qual Health Res 2002;12:329-46.

92. Costantini L, Beanlands H, McCay E, et al. The self-management experience of people with mild to moderate chronic kidney disease. Nephrol Nurs J 2008:35:147-55.

93. Lopez-Vargas PA, Tong A, Howell M, et al. Patient awareness and beliefs about the risk factors and comorbidities associated with chronic kidney disease : a mixed-methods study. Nephrology 2017;22:374-81.

94. Lopez-Vargas PA, Tong A, Phoon RK, et al. Knowledge deficit of patients with stage 1-4 CKD: a focus group study. Nephrology 2014:19:234-43.

95. Mason J, Stone M, Khunti K, et al. Educational needs for blood pressure control in chronic kidney disease. $J$ Ren Care 2007:33:134-8.

96. Muduma G, Shupo FC, Dam S, et al. Patient survey to identify reasons for non-adherence and elicitation of quality of life concepts associated with immunosuppressant therapy in kidney transplant recipients. Patient Prefer Adherence 2016;10:27-36.

97. Noble H, Kelly D, Hudson P. Experiences of carers supporting dying renal patients managed without dialysis. J Adv Nurs 2013;69:1829-39.

98. Noble $\mathrm{H}$, Meyer J, Bridges J, et al. Examining renal patients' death trajectories without dialysis. End of Life Care 2010;4:26-34.

99. Rifkin DE, Laws MB, Rao M, et al. Medication adherence behavio and priorities among older adults with CKD: a semistructured interview study. Am J Kidney Dis 2010;56:439-46.

100. Vélez E, Ramasco M. Meaning of illness and illness representations, crucial factors to integral care. Edtna Erca J 2006;32:81-5.

101. Williams AF, Manias E. Perceptions of pain control by consumers with chronic kidney disease. J Nurs Healthc Chronic IIIn 2009;1:199-209.

102. Williams AF, Manias E, Walker R. Adherence to multiple, prescribed medications in diabetic kidney disease: a qualitative study of consumers' and health professionals' perspectives. Int J Nurs Stud 2008; $45: 1742-56$

103. RARd S, VLd S, GJNd O, et al. Coping strategies used by chronic renal failure patients on hemodialysis. Escola Anna Nery - Revista de Enfermagem 2016;20:147-54.

104. Al-Arabi S. Quality of life: subjective descriptions of challenges to patients with end stage renal disease. Nephrol Nurs $J$ 2006;33:285-92.

105. Bourbonnais FF, Tousignant KF. The pain experience of patients on maintenance hemodialysis. Nephrol Nurs J 2012;39:13-19.

106. Clarkson KA, Robinson K. Life on dialysis: a lived experience. Nephrol Nurs J 2010;37:29-35.

107. Aasen EM, Kvangarsnes M, Heggen K. Perceptions of patient participation amongst elderly patients with end-stage renal disease in a dialysis unit. Scand J Caring Sci 2012;26:61-9.

108. Richard CJ, Engebretson J. Negotiating living with an arteriovenous fistula for hemodialysis. Nephrol Nurs J 2010;37:363-74.

109. Tweed AE, Ceaser K. Renal replacement therapy choices for predialysis renal patients. Br J Nurs 2005;14:659-64.

110. Xi W, Harwood L, Diamant MJ, et al. Patient attitudes towards the arteriovenous fistula: a qualitative study on vascular access decision making. Nephrol Dial Transplant 2011;26:3302-8.

111. Taylor MJ, Hanson CS, Casey JR, et al. "You know your own fistula, it becomes a part of you"-Patient perspectives on vascular access: a semistructured interview study. Hemodial Int 2016;20:5-14.

112. Yu J, Ng HJ, Nandakumar M, et al. The management of food cravings and thirst in hemodialysis patients: a qualitative study. $J$ Health Psychol 2016;21:217-27.
113. Cristóvão AF. Dificultades y estrategias en el manejo del régimen terapéutico en el paciente renal crónico en hemodiálisis. Enfermería Nefrológica 2013;16:247-55

114. Gricio TC, Kusumotal L, MIdL Cândido. Perceptions and knowledge of patients with chronic kidney disease under conservative treatment. Rev Eletr Enf 2009;11:884-93.

115. Hagren B, Pettersen IM, Severinsson E, et al. Maintenance haemodialysis: patients' experiences of their life situation. J Clin Nurs 2005;14:294-300

116. Herbias LH, Soto RA, Figueroa HB, et al. Meaning of quality of life in patients on hemodialysis therapy: a phenomenological study. Revista de la Sociedad Espanola de Enfermeria Nefrologica 2016;19:37-44

117. Tovazzi ME, Mazzoni V. Personal paths of fluid restriction in patients on hemodialysis. Nephrol Nurs J 2012;39:207-15.

118. Avril-Sephula B, Meekums B, Jackson C. How do partners living with haemodialysis patients cope? Journal of Renal Nursing 2014;6:133-7.

119. Roso CC, Beuter M, Kruse MHL, et al. Self-care of patients in conservative treatment of chronic renal insufficiency. Text Context Nursing 2013;22:739-45.

120. Hong LI, Wang W, Chan EY, et al. Dietary and fluid restriction perceptions of patients undergoing haemodialysis: an exploratory study. J Clin Nurs 2017;26:3664-76.

121. de Brito-Ashurst I, Perry L, Sanders TA, et al. Barriers and facilitators of dietary sodium restriction amongst Bangladeshi chronic kidney disease patients. J Hum Nutr Diet 2011;24:86-95.

122. Theofilou $P$, Synodinou $C$, Panagiotaki H. Undergoing haemodialysis: a qualitative study to investigate the lived experiences of patients. Europe's Journal of Psychology 2013:9:19-32

123. Shirazian S, Crnosija N, Weinger K, et al. The self-management experience of patients with type 2 diabetes and chronic kidney disease: A qualitative study. Chronic IIIn 2016;12:18-28.

124. Walker R, James H, Burns A. Adhering to behaviour change in older pre-dialysis populations-what do patients think? A qualitative study. $J$ Ren Care 2012;38:34-42.

125. Kierans C, Padilla-Altamira C, Garcia-Garcia G, et al. When health systems are barriers to health care: challenges faced by uninsured Mexican kidney patients. PLoS One 2013;8:e54380.

126. Bristowe K, Horsley HL, Shepherd K, et al. Thinking ahead-the need for early advance care planning for people on haemodialysis: a qualitative interview study. Palliat Med 2015;29:443-50.

127. Tonkin-Crine S, Okamoto I, Leydon GM, et al. Understanding by older patients of dialysis and conservative management for chronic kidney failure. Am J Kidney Dis 2015;65:443-50.

128. Johnston $\mathrm{S}$, Noble H. Factors influencing patients with stage 5 chronic kidney disease to opt for conservative management: a practitioner research study. J Clin Nurs 2012;21(9-10):1215-22.

129. Lo $C$, llic $D$, Teede $H$, et al. The perspectives of patients on health-care for co-morbid diabetes and chronic kidney disease: a qualitative study. PLoS One 2016;11:e0146615.

130. Prieto MA, Escudero MJ, Suess A, et al. Patients' opinions and expectations about the dialysis care process. An Sist Sanit Navar 2011;34:21-31.

131. IaS R, Larrea AA, OGa U, et al. Withdrawing dialysis in Endstage renal disease: What do patients think? Enferm Nefrol 2014;17:110-9.

132. Yngman-Uhlin P, Fogelberg A, Uhlin F. Life in standby: hemodialysis patients' experiences of waiting for kidney transplantation. $J$ Clin Nurs 2016;25(1-2):92-8.

133. Moran A, Scott A, Darbyshire P. Waiting for a kidney transplant: patients' experiences of haemodialysis therapy. J Adv Nurs 2011;67:501-9.

134. Axelsson L, Klang B, Lundh Hagelin C, et al. End of life of patients treated with haemodialysis as narrated by their close relatives. Scand J Caring Sci 2015;29:776-84.

135. Yngman-Uhlin P, Friedrichsen M, Gustavsson M, et al. Circling around in tiredness: perspectives of patients on peritoneal dialysis. Nephrol Nurs J 2010;37:407-13

136. Axelsson L, Randers I, Jacobson SH, et al. Living with haemodialysis when nearing end of life. Scand J Caring Sci 2012;26:45-52.

137. Heiwe S, Clyne N, Dahlgren MA. Living with chronic renal failure: patients' experiences of their physical and functional capacity. Physiother Res Int 2003;8:167-77.

138. Horigan AE, Schneider SM, Docherty S, et al. The experience and self-management of fatigue in patients on hemodialysis. Nephrol Nurs J 2013;40:113-22.

139. White N, Richter J, Koeckeritz J, et al. "Going Forward": Family resiliency in patients on hemodialysis. J Fam Nurs 2004;10:357-78. 
140. Heiwe S, Dahlgren MA. Living with chronic renal failure: Coping with physical activities of daily living. Adv Physiother 2004;6:147-57.

141. Rabiei L, Eslami AA, Abedi H, et al. Caring in an atmosphere of uncertainty: perspectives and experiences of caregivers of peoples undergoing haemodialysis in Iran. Scand J Caring Sci 2016;30:594-601.

142. Shahgholian N, Yousefi $\mathrm{H}$. Supporting hemodialysis patients: a phenomenological study. Iran J Nurs Midwifery Res 2015;20:626-33.

143. Yeun EJ, Bang HY, Kim EJ, et al. Attitudes toward stress and coping among primary caregivers of patients undergoing hemodialysis: a Q-methodology study. Hemodial Int 2016;20:453-62.

144. Yumang MJ, Hammond L, Filteau N, et al. Perceptions of risk for foot problems and foot care practices of patients on hemodialysis. Nephrol Nurs J 2009;36:509-16.

145. Barbosa GDS, Valadares GV. Hemodialysis: patient's adaptation and life style. Acta Paul Enferm 2009;22(Especial Nefrologia:524-7.

146. Calvey D, Mee L. The lived experience of the person dependent on haemodialysis. J Ren Care 2011;37:201-7.

147. Krespi R, Bone M, Ahmad R, et al. Haemodialysis patients beliefs about renal failure and its treatment. Patient Educ Couns 2004;53:189-96.

148. Cox KJ, Parshall MB, Hernandez SHA, et al. Symptoms among patients receiving in-center hemodialysis: a qualitative study. Hemodial Int 2017;21:524-33.

149. Machado LRC, Car MR. A dialetic of patients' daily life with chronic renal failure in hemodialysis: the unavoidable and the casual. Rev Esc Enferm USP 2003;37:27-35.

150. Moran A, Scott PA, Darbyshire P. Existential boredom: the experience of living on haemodialysis therapy. Med Humanit 2009;35:70-5

151. Krespi Boothby MR, Salmon P. [Self-efficacy and hemodialysis treatment: a qualitative and quantitative approach]. Turk Psikiyatri Derg 2013;24:84-93.

152. Tong A, Palmer S, Manns B, et al. The beliefs and expectations of patients and caregivers about home haemodialysis: an interview study. BMJ Open 2013;3:e002148.

153. Torchi TS, STCd A, Guimarães AM AGM, et al. Clinical conditions and health care demand behavior of chronic renal patients. Acta Paul Enferm 2014;27:585-90.

154. Cadena DMaGn, GPAb H, Atilano BF, et al. Anchored to a machine: experiences of patients with chronic kidney disease. Revista CONAMED 2015;20(S1):16-20.

155. Klava dos Reis C, Guirardello EB, Gomes Campos CJ. [The person with renal chronic disease and caring demands]. Rev Bras Enferm 2008:61:336-41.

156. Baillie J, Lankshear A. Patient and family perspectives on peritonea dialysis at home: findings from an ethnographic study. $J$ Clin Nurs 2015;24(1-2):222-34.

157. Baillie J, Lankshear A. Patients' and relatives' experiences of peritonitis when using peritoneal dialysis. J Ren Care 2015:41:177-86.

158. Xi W, Singh PM, Harwood L, et al. Patient experiences and preferences on short daily and nocturnal home hemodialysis. Hemodial Int 2013;17:201-7.

159. Giles S. Transformations: a phenomenological investigation into the life-world of home haemodialysis. Soc Work Health Care 2004;38:29-50.

160. Giles S. Struggles between the body and machine: the paradox of living with a home haemodialysis machine. Soc Work Health Care 2005;41:19-35

161. Low J, Myers J, Smith G, et al. The experiences of close persons caring for people with chronic kidney disease stage 5 on conservative kidney management: contested discourses of ageing. Health 2014;18:613-30.

162. FKd S, Valadares GV. Living between the nightmare and the awakening - the first time in dealing with peritoneal dialysis. Escola Anna Nery - Revista de Enfermagem 2011;15:39-46.

163. McCarthy A, Shaban R, Boys J, et al. Compliance, normality, and the patient on peritoneal dialysis. Nephrol Nurs J 2010;37:243-50.

164. Chong HJ, Kim HK, Kim SR, et al. Waiting for a kidney transplant: the experience of patients with end-stage renal disease in South Korea. J Clin Nurs 2016;25(7-8):930-9.

165. Flores RV, Thome EG. Feelings of patients on the waiting list for a kidney transplant]. Rev Bras Enferm 2004;57:687-90.

166. Kierans $C$. Narrating kidney disease: the significance of sensation and time in the emplotment of patient experience. Cult Med Psychiatry 2005;29:341-59.

167. Kierans CM, Maynooth NUI. Sensory and narrative identity: the narration of illness process among chronic renal sufferers in Ireland. Anthropol Med 2001;8(2-3):237-53.
168. Knihs NDS, Sartori DL, Zink V, et al. The experience of patients who need renal transplantation while waiting for a compatible organ. Text Context Nursing 2013;22:1160-8.

169. Lawrence $C$, Sharma S, Da Silva-Gane M, et al. Exploring the views of patients not on the transplant waiting list: a qualitative study. $J$ Ren Care 2013;39:118-24.

170. Lopes SGR, Silva DMGVda. Narratives of women on hemodialysis: waiting for a kidney transplant. Texto \& Contexto - Enfermagem 2014:23:680-7.

171. Spiers J, Smith JA. Waiting for a kidney from a deceased donor: an interpretative phenomenological analysis. Psychol Health Med 2016;21:836-44.

172. Wachterman MW, McCarthy EP, Marcantonio ER, et al. Mistrust, misperceptions, and miscommunication: a qualitative study of preferences about kidney transplantation among African Americans. Transplant Proc 2015;47:240-6.

173. Allen $D$, Wainwright $M$, Hutchinson T. 'Non-compliance' as illness management: Hemodialysis patients' descriptions of adversarial patient-clinician interactions. Soc Sci Med 2011;73:129-34.

174. Sieverdes JC, Nemeth LS, Magwood GS, et al. African American kidney transplant patients' perspectives on challenges in the living donation process. Prog Transplant 2015;25:164-75.

175. Boaz A, Morgan M. Working to establish 'normality' post-transplant: a qualitative study of kidney transplant patients. Chronic IIIn 2014;10:247-58.

176. Goldade K, Sidhwani S, Patel S, et al. Kidney transplant patients' perceptions, beliefs, and barriers related to regular nephrology outpatient visits. Am J Kidney Dis 2011;57:11-20.

177. Spiers J, Smith JA, Drage M. A longitudinal interpretative phenomenological analysis of the process of kidney recipients resolution of complex ambiguities within relationships with their living donors. J Health Psychol 2015 (published Online First: 2015/05/02).

178. Stanfill A, Bloodworth R, Cashion A. Lessons learned: experiences of gaining weight by kidney transplant recipients. Prog Transplant 2012;22:71-8.

179. Tielen M, van Exel NJ, van Buren MC, et al. Attitudes towards medication non-adherence in elderly kidney transplant patients: a $Q$ methodology study. Nephrol Dial Transplant 2011;26:1723-8.

180. Gordon EJ, Prohaska TR, Gallant MP, et al. Adherence to immunosuppression: a prospective diary study. Transplant Proc 2007;39:3081-5.

181. Leung SS, Shiu AT. Experience of Hong Kong patients awaiting kidney transplantation in mainland China. J Clin Nurs 2007;16:341-9.

182. Orr A, Orr D, Willis S, et al. Patient perceptions of factors influencing adherence to medication following kidney transplant. Psychol Health Med 2007;12:509-17.

183. Orr A, Willis S, Holmes M, et al. Living with a kidney transplant: a qualitative investigation of quality of life. $J$ Health Psychol 2007;12:653-62.

184. Schipper K, Abma TA, Koops C, et al. Sweet and sour after renal transplantation: a qualitative study about the positive and negative consequences of renal transplantation. Br J Health Psychol 2014:19:580-91.

185. Wiederhold D, Langer G, Landenberger M. Ambivalent lived experiences and instruction need of patients in the early period after kidney transplantation: a phenomenological study. Nephrol Nurs J 2011;38:417-23.

186. Buldukoglu K, Kulakac O, Kececioglu N, et al. Recipients??? Perceptions of their transplanted kidneys. Transplantation 2005;80:471-6.

187. Axelsson L, Randers I, Lundh Hagelin C, et al. Thoughts on death and dying when living with haemodialysis approaching end of life. $J$ Clin Nurs 2012;21(15-16):2149-59.

188. Chatrung $\mathrm{C}$, Sorajjakool S, Amnatsatsue K. Wellness and religious coping among thai individuals living with chronic kidney disease in southern california. J Relig Health 2015;54:2198-211.

189. Hain DJ, Wands L, Liehr P. Approaches to resolve health challenges in a population of older adults undergoing hemodialysis. Res Gerontol Nurs 2011;4:53-62.

190. Lin CC, Han CY, Pan IJ. A qualitative approach of psychosocial adaptation process in patients undergoing long-term hemodialysis. Asian Nurs Res 2015;9:35-41.

191. Rodrigues DFD, Schwartz E, MdG S, et al. Experience of men undergoing hemodialysis about their sexuality. Avengerm 2011;XXIX:255-62.

192. Tanyi RA, Werner JS. Women's experience of spirituality within end-stage renal disease and hemodialysis. Clin Nurs Res 2008;17:32-49. 
193. Tanyi RA, Werner JS. Toward a trajectory of adjustment in women with end-stage renal disease on haemodialysis. J Clin Nurs 2008;17(5A):43-50.

194. Martin-McDonald K. Being dialysis-dependent: a qualitative perspective. Collegian 2003;10:29-33.

195. MartinMcDonald K. Dialysis-dependency: the reformulated or remnant person. Contemp Nurse 2004:16(1-2):151-61.

196. $\mathrm{H}-\mathrm{y} \mathrm{N}, \mathrm{J}-\mathrm{f} \mathrm{L}$. The psychological trajectory from diagnosis to approaching end of life in patients undergoing hemodialysis in China: a qualitative study. International Journal of Nursing Sciences 2017:4:29-33.

197. Bennett PN, Bonner A, Andrew J, et al. Using images to communicate the hidden struggles of life on dialysis. J Commun Healthc 2013;6:12-21.

198. Costa FG, Coutinho MdaPdeL, Santana IOde. Insuficiência renal crônica: representações sociais de pacientes com e sem depressão. Psico-USF 2014;19:387-98.

199. Yodchai K, Dunning T, Hutchinson AM, et al. How do Thai patients with end stage renal disease adapt to being dependent on haemodialysis?: a pilot study. J Ren Care 2011;37:216-23.

200. Arslan SY, Ege E. Sexual experiences of women exposed to hemodialysis treatment. Sex Disabil 2009;27:215-21.

201. Tanyi RA, Werner JS, Recine AC, et al. Perceptions of incorporating spirituality into their care: a phenomenological study of female patients on hemodialysis. Nephrol Nurs J 2006;33:532-8.

202. Ladin K, Lin N, Hahn E, et al. Engagement in decision-making and patient satisfaction: a qualitative study of older patients' perceptions of dialysis initiation and modality decisions. Nephrol Dial Transplant 2017;32:gfw307.

203. Erlang AS, Nielsen $\mathrm{IH}$, Hansen $\mathrm{HO}$, et al. Patients experiences of involvement in choice of dialysis mode. J Ren Care 2015;41:260-7.

204. Moran A, Scott AP, Darbyshire P. Communicating with nurses: patients' views on effective support while on haemodialysis. Nurs Times 2009;105:42146.

205. Mitchell A, Farrand P, James H, et al. Patients' experience of transition onto haemodialysis: a qualitative study. J Ren Care 2009;35:99-107.

206. Schober GS, Wenger JB, Lee CC, et al. Dialysis Patient Perspectives on CKD Advocacy: a semistructured interview Study. Am J Kidney Dis 2017;69:29-40.

207. Smith K, Coston M, Glock K, et al. Patient perspectives on fluid management in chronic hemodialysis. J Ren Nutr 2010;20:334-41.

208. Pietrovsk V, Dall'Agnol CM. Situações significativas no espaçocontexto da hemodiálise: o que dizem os usuários de um serviço? Rev Bras Enferm 2006;59:630-5.

209. Malheiro Oliveira P, Arruda Soares D. Percepciones de las personas con insuficiencia renal crónica sobre la calidad de vida. Enfermería Global 2012;28:257-75.

210. Beanlands $\mathrm{H}$, Horsburgh ME, Fox S, et al. Caregiving by family and friends of adults receiving dialysis. Nephrol Nurs J 2005;32:621-31.

211. Ziegert K, Fridlund B, Lidell E. Health in everyday life among spouses of haemodialysis patients: a content analysis. Scand $J$ Caring Sci 2006;20:223-8.

212. Ziegert K, Fridlund B, Lidell E. "Time for dialysis as time to live": experiences of time in everyday life of the Swedish next of kin of hemodialysis patients. Nurs Health Sci 2009;11:45-50.

213. Ziegert K, Fridlund B. Conceptions of life situation among next-ofkin of haemodialysis patients. J Nurs Manag 2001;9:231-9.

214. Eslami AA, Rabiei L, Abedi HA, et al. Coping skills of Iranian family careivers in caretaking of patients undergoing haemodialysis: a qualitative study. Journal of renal care 2016; XX(XX):1-10.

215. Taylor F, Gutteridge R, Willis C. Peer support for CKD patients and carers: overcoming barriers and facilitating access. Health Expect 2016;19:617-30.

216. Tavares JM, Lisboa MT, Ferreira MA, et al. Peritoneal dialysis: family care for chronic kidney disease patients in home-based treatment. Rev Bras Enferm 2016;69:1172-8.

217. Lovink MH, Kars MC, de Man-van Ginkel JM, et al. Patients' experiences of safety during haemodialysis treatment - a qualitative study. J Adv Nurs 2015;71:2374-83.

218. Nagpal N, Boutin-Foster C, Melendez J, et al. Experiences of patients undergoing dialysis who are from ethnic and racial minorities. J Ren Care 2017:43:29-36.

219. Cramm JM, Leensvaart L, Berghout $M$, et al. Exploring views on what is important for patient-centred care in end-stage renal disease using Q methodology. BMC Nephrol 2015;16:74):74.

220. Namiki S, Rowe J, Cooke M. Living with home-based haemodialysis: insights from older people. J Clin Nurs 2010;19(34):547-55.

221. DePasquale N, Ephraim PL, Ameling J, et al. Selecting renal replacement therapies: what do African American and non-African
American patients and their families think others should know? A mixed methods study. BMC Nephrol 2013;14:9.

222. Sahaf RP, Sadat Ilali EPS, Peyrovi HP, et al. Uncertainty, the overbearing lived experience of the elderly people undergoing Hemodialysis: a qualitative study. Int J Community Based Nurs Midwifery 2017;5:13-21.

223. Lee A, Gudex C, Povlsen JV, et al. Patients' views regarding choice of dialysis modality. Nephrol Dial Transplant 2008;23:3953-9.

224. Piccoli GB, Consiglio V, Deagostini MC, et al. Starting together: a focus group for the organization of a CKD outpatient care unit. Journal of nephrology 2010;23:699-704.

225. Pilger C, Rampari EM, Waidman MAP, et al. Hemodialysis: its meaning and impact in the elderly life. Escola Anna Nery - Revista de Enfermagem 2010;14:677-83.

226. Browne T, Amamoo A, Patzer RE, et al. Everybody needs a cheerleader to get a kidney transplant: a qualitative study of the patient barriers and facilitators to kidney transplantation in the Southeastern United States. BMC Nephrol 2016;17:108.

227. Hollingdale R, Sutton D, Hart K. Facilitating dietary change in renal disease: investigating patients' perspectives. J Ren Care 2008;34:136-42.

228. Marques FRB, Botelho MR, Marcon SS, et al. Coping strategies used by family members of individuals receiving hemodialysis. Texto \& Contexto - Enfermagem 2014;23:915-24.

229. Russ AJ, Shim JK, Kaufman SR. "Is there life on dialysis?": time and aging in a clinically sustained existence. Med Anthropol 2005;24:297-324.

230. Winterbottom A, Bekker HL, Conner M, et al. Choosing dialysis modality: decision making in a chronic illness context. Health Expect 2014;17:710-23.

231. Davison SN. Facilitating advance care planning for patients with end-stage renal disease: the patient perspective. Clin J Am Soc Nephrol 2006;1:1023-8.

232. Iles-Smith H. Perceptions and experiences of pre-dialysis patients. Edtna Erca J 2005;31:130-3.

233. Wilkinson E, Randhawa G, Brown EA, et al. Communication as care at end of life: an emerging issue from an exploratory action research study of renal end-of-life care for ethnic minorities in the UK. J Ren Care 2014;40 Suppl 1(S1):23-9.

234. Campos CJG, Turato ER. The professional health team, the renal patient undergoing hemodialysis and interpersonal relationships. Rev Bras Enferm 2003;56:508-12.

235. Bailey PK, Ben-Shlomo Y, de Salis I, et al. Better the donor you know? A qualitative study of renal patients' views on 'altruistic' livedonor kidney transplantation. Soc Sci Med 2016;150:104-11.

236. Nygårdh A, Malm D, Wikby K, et al. The experience of empowerment in the patient-staff encounter: the patient's perspective. J Clin Nurs 2012;21(5-6):897-904.

237. Tong A, Gow K, Wong G, et al. Patient perspectives of a young adult renal clinic: a mixed-methods evaluation. Nephrology 2015;20:352-9.

238. Bridger J. Enabling patients with chronic kidney disease to selfcare. Journal of Renal Nursing 2009;1:173-8.

239. Ghadami A, Memarian R, Mohamadi E, et al. Patients' experiences from their received education about the process of kidney transplant: a qualitative study. Iran J Nurs Midwifery Res 2012;17(2 Sup1):157-64.

240. Haspeslagh A, De Bondt K, Kuypers D, et al. Completeness and satisfaction with the education and information received by patients immediately after kidney transplant: a mixed-models study. Prog Transplant 2013;23:12-22.

241. Russell CL, Kilburn E, Conn VS, et al. Medication-taking beliefs of adult renal transplant recipients. Clin Nurse Spec 2003;17:200-8.

242. Urstad KH, Wahl AK, Andersen MH, et al. Renal recipients' educational experiences in the early post-operative phase-a qualitative study. Scand J Caring Sci 2012;26:635-42.

243. Calestani M, Tonkin-Crine S, Pruthi R, et al. Patient attitudes towards kidney transplant listing: qualitative findings from the ATTOM study. Nephrol Dial Transplant 2014;29:2144-50.

244. Ros RL, Kucirka LM, Govindan P, et al. Patient attitudes toward $\mathrm{CDC}$ high infectious risk donor kidney transplantation: inferences from focus groups. Clin Transplant 2012;26:247-53.

245. Sheu J, Ephraim PL, Powe NR, et al. African American and nonAfrican American patients' and families' decision making about renal replacement therapies. Qual Health Res 2012;22:997-1006.

246. Aasen EM, Kvangarsnes M, Wold B, et al. The next of kin of older people undergoing haemodialysis: a discursive perspective on perceptions of participation. J Adv Nurs 2012;68:1716-25.

247. EGdR Thomé, Meyer DEE. Women caregivers for men with chronic kidney disease: a cultural approach. Text Context Nursing 2011:20:503-11. 
248. Harwood L, Locking-Cusolito H, Spittal J, et al. Preparing for hemodialysis: patient stressors and responses. Nephrol Nurs $J$ 2005;32:295-302.

249. Yodchai K, Dunning T, Savage S, et al. The role of religion and spirituality in coping with kidney disease and haemodialysis in Thailand. Scand J Caring Sci 2017;31:359-67.

250. Wise M, Schatell D, Klicko K, et al. Successful daily home hemodialysis patient-care partner dyads: benefits outweigh burdens. Hemodial Int 2010;14:278-88.

251. Calvin AO. Haemodialysis patients and end-of-life decisions: a theory of personal preservation. J Adv Nurs 2004;46:558-66.

252. Bath J, Tonks S, Edwards P. Psychological care of the haemodialysis patient. Edtna Erca J 2003;29:85-8.

253. Weil CM. Exploring hope in patients with end stage renal disease on chronic hemodialysis. Nephrol Nurs J 2000;27:219-24.

254. Wells SA. Occupational deprivation or occupational adaptation of Mexican Americans on renal dialysis. Occup Ther Int 2015;22:174-82.

255. Wilson PM, Reston JD, Bieraugel R, et al. You cannot choose your family: sociological ambivalence in the hemodialysis unit. Qual Health Res 2015;25:27-39.

256. Lenci LT, Campbell JD. Peritoneal dialysis in elderly patients. Adv Perit Dial 2012;28:79-83.

257. Walton J. Prayer warriors: a grounded theory study of American Indians receiving hemodialysis. Nephrol Nurs J 2007;34:377-86.

258. Walton J. Finding a balance: a grounded theory study of spirituality in hemodialysis patients. Nephrol Nurs $J$ 2002;29:447-56.

259. BPd S, Schwartz E, Beuter M, et al. Consequences attributed to kidney transplantation: critical incident technique. Texto \& Contexto - Enfermagem 2015;24:748-55.

260. Ravenscroft EF. Diabetes and kidney failure: how individuals with diabetes experience kidney failure. Nephrol Nurs $J$ 2005;32:502-10

261. Williams AF, Manias E, Walker R. The role of irrational thought in medicine adherence: people with diabetic kidney disease. J Adv Nurs 2009;65:2108-17

262. Bäckström-Andersson $\mathrm{H}$, Lindberg $\mathrm{B}$, Lindström $\mathrm{R}$. Dry weight from the haemodialysis patient perspective. Renal Society of Australasia Journal 2013;9:68-73.

263. Vestman C, Hasselroth M, Berglund M. Freedom and confinement: Patients' experiences of life with home haemodialysis. Nurs Res Pract 2014;2014:1-7.

264. Curtin RB, Mapes D, Petillo $M$, et al. Long-term dialysis survivors: a transformational experience. Qual Health Res 2002;12:609-24.

265. Curtin RB, Mapes DL. Health care management strategies of longterm dialysis survivors. Nephrol Nurs J 2001;28:385-92.

266. Lederer S, Fischer MJ, Gordon HS, et al. Barriers to effective communication between veterans with chronic kidney disease and their healthcare providers. Clin Kidney J 2015;8:766-71.

267. McKillop G, Joy J. Patients' experience and perceptions of polypharmacy in chronic kidney disease and its impact on adherent behaviour. J Ren Care 2013;39:200-7.

268. Reid K, Morris M, Cormack M, et al. Exploring the process of adjusting to diabetic kidney disease. J Ren Care 2012;38 Suppl 1:30-9.

269. Ladin K, Buttafarro K, Hahn E, et al. "End-of-life care? I'm not going to worry about that yet." Health literacy gaps and endof-life planning among elderly dialysis patients. Gerontologist 2017;00:1-10.

270. Harwood L, Clark AM. Dialysis modality decision-making for older adults with chronic kidney disease. J Clin Nurs 2014;23(2324):3378-90.

271. Llewellyn H, Low J, Smith G, et al. Narratives of continuity among older people with late stage chronic kidney disease who decline dialysis. Soc Sci Med 2014;114:49-56.

272. Schell JO, Patel UD, Steinhauser KE, et al. Discussions of the kidney disease trajectory by elderly patients and nephrologists: a qualitative study. Am J Kidney Dis 2012;59:495-503.

273. Walker RC, Morton RL, Tong A, et al. Patient and caregiver preferences for home dialysis-the home first study: a protocol for qualitative interviews and discrete choice experiments. BMJ Open 2015;5:e007405

274. Landreneau K, Ward-Smith P. Patients' perceptions concerning choice among renal replacement therapies: a pilot study. Nephrol Nurs J 2006;33:397-402.

275. Shaw R. Being-in-dialysis: The experience of the machine-body for home dialysis users. Health 2015;19:229-44.

276. Visser A, Dijkstra GJ, Kuiper D, et al. Accepting or declining dialysis: considerations taken into account by elderly patients with endstage renal disease. J Nephrol 2009;22:794-9.
277. de Rosenroll A, Higuchi KS, Dutton KS, et al. Perspectives of significant others in dialysis modality decision-making: a qualitative study. Cannt J 2013;23:17-24.

278. Landreneau KJ, Ward-Smith P. Perceptions of adult patients on hemodialysis concerning choice among renal replacement therapies. Nephrol Nurs J 2007;34:513-9.

279. Cases A, Dempster M, Davies M, et al. The experience of individuals with renal failure participating in home haemodialysis: an interpretative phenomenological analysis. J Health Psychol 2011;16:884-94.

280. Lindsay $H$, MacGregor C, Fry M. The experience of living with chronic illness for the haemodialysis patient: an interpretative phenomenological analysis. Health Sociology Review 2014;23:232-41.

281. Darrell L. Faith that God cares: the experience of spirituality with African American hemodialysis patients. Social Work \& Christianity 2016;43:189-212.

282. Hagren B, Pettersen I-M, Severinsson E, et al. The haemodialysis machine as a lifeline: experiences of suffering from end-stage renal disease. J Adv Nurs 2001;34:196-202.

283. Harrington J, Morgan M. Understanding kidney transplant patients' treatment choices: the interaction of emotion with medical and social influences on risk preferences. Soc Sci Med 2016;155:43-50.

284. Herlin C, Wann-Hansson C. The experience of being 30-45 years of age and depending on haemodialysis treatment: a phenomenological study. Scand J Caring Sci 2010;24:693-9.

285. Lewis $\mathrm{H}$, Arber $\mathrm{S}$. The role of the body in end-stage kidney disease in young adults: Gender, peer and intimate relationships. Chronic IIIn 2015;11:184-97.

286. Pelletier-Hibbert M, Sohi P. Sources of uncertainty and coping strategies used by family members of individuals living with end stage renal disease. Nephrol Nurs J 2001;28:411-9.

287. Aasen EM. A comparison of the discursive practices of perception of patient participation in haemodialysis units. Nurs Ethics 2015;22:341-51.

288. Goff SL, Eneanya ND, Feinberg R, et al. Advance care planning: a qualitative study of dialysis patients and families. Clin J Am Soc Nephrol 2015;10:390-400.

289. Nygårdh A, Wikby K, Malm D, et al. Empowerment in outpatient care for patients with chronic kidney disease - from the family member's perspective. BMC Nurs 2011;10:21.

290. Hutchison LA, Raffin-Bouchal DS, Syme CA, et al. Readiness to participate in advance care planning: a qualitative study of renal failure patients, families and healthcare providers. Chronic IIIn 2017;13:171-87.

291. Davison SN, Simpson C. Hope and advance care planning in patients with end stage renal disease: qualitative interview study. BMJ 2006;333:886.

292. Calvin AO, Engebretson JC, Sardual SA. Understanding of advance care planning by family members of persons undergoing hemodialysis. West J Nurs Res 2014;36:1357-73.

293. Noble H, Meyer J, Bridges J, et al. Reasons renal patients give for deciding not to dialyze: a prospective qualitative interview study. Dial Transplant 2009;38:82-9.

294. Molzahn A, Sheilds L, Bruce A, et al. Perceptions regarding death and dying of individuals with chronic kidney disease. Nephrol Nurs J 2012;39:197-204.

295. Casey JR, Hanson CS, Winkelmayer WC, et al. Patients' perspectives on hemodialysis vascular access: a systematic review of qualitative studies. Am J Kidney Dis 2014;64:937-53.

296. Jamieson NJ, Hanson CS, Josephson MA, et al. Motivations, challenges, and attitudes to self-management in kidney transplant recipients: a Systematic review of qualitative studies. Am J Kidney Dis 2016;67:461-78.

297. Palmer SC, Hanson CS, Craig JC, et al. Dietary and fluid restrictions in CKD: a thematic synthesis of patient views from qualitative studies. Am J Kidney Dis 2015;65:559-73.

298. Ralph A, Chapman JR, Gillis J, et al. Family perspectives on deceased organ donation: thematic synthesis of qualitative studies. Am J Transplant 2014;14:923-35.

299. Tong A, Brown MA, Winkelmayer WC, et al. Perspectives on pregnancy in women with ckd: a semistructured interview study. Am J Kidney Dis 2015;66:951-61.

300. Tong A, Chapman JR, Wong G, et al. The experiences of commercial kidney donors: thematic synthesis of qualitative research. Transpl Int 2012;25:1138-49.

301. Tong A, Cheung KL, Nair SS, et al. Thematic synthesis of qualitative studies on patient and caregiver perspectives on end-of-life care in CKD. Am J Kidney Dis 2014;63:913-27. 
302. Tong A, Jesudason S, Craig JC, et al. Perspectives on pregnancy in women with chronic kidney disease: systematic review of qualitative studies. Nephrol Dial Transplant 2015;30:652-61.

303. Tong A, Lowe A, Sainsbury P, et al. Experiences of parents who have children with chronic kidney disease: a systematic review of qualitative studies. Pediatrics 2008;121:349-60.

304. Tong A, Rangan GK, Ruospo M, et al. A painful inheritancepatient perspectives on living with polycystic kidney disease: thematic synthesis of qualitative research. Nephrol Dial Transplant 2015;30:790-800.

305. Walker RC, Hanson CS, Palmer SC, et al. Patient and caregiver perspectives on home hemodialysis: a systematic review. Am J Kidney Dis 2015;65:451-63.

306. Tong A, Hanson CS, Chapman JR, et al. 'Suspended in a paradox'-patient attitudes to wait-listing for kidney transplantation: systematic review and thematic synthesis of qualitative studies. Transpl Int 2015;28:771-87.

307. Bailey P, Tomson C, Risdale S, et al. From potential donor to actual donation: does socioeconomic position affect living kidney donation? A systematic review of the evidence. Transplantation 2014;98:918-26.

308. Reid C, Seymour J, Jones C. A thematic synthesis of the experiences of adults living with hemodialysis. Clin J Am Soc Nephrol 2016;11:1206-18.

309. Arokiasamy $\mathrm{P}$, Uttamacharya $\mathrm{U}$, Jain $\mathrm{K}$, et al. The impact of multimorbidity on adult physical and mental health in low- and middle-income countries: what does the study on global ageing and adult health (SAGE) reveal? BMC Med 2015;13:178.

310. Kim TJ, Vonneilich N, Lüdecke D, et al. Income, financial barriers to health care and public health expenditure: a multilevel analysis of 28 countries. Soc Sci Med 2017;176:158-65.

311. Mackenbach JP, Looman CWN, Artnik B, et al. 'Fundamental causes' of inequalities in mortality: an empirical test of the theory in 20 European populations. Sociol Health Illn 2017:39:1117-33.

312. Prasad N, Jha V. Hemodialysis in Asia. Kidney Dis 2015;1:165-77.

313. Rajapurkar MM, John GT, Kirpalani AL, et al. What do we know about chronic kidney disease in India: first report of the Indian CKD registry. BMC Nephrol 2012;13:10.

314. Obrador GT, Rubilar X, Agazzi E, et al. The challenge of providing renal replacement therapy in developing countries: the latin American perspective. Am J Kidney Dis 2016;67:499-506.

315. Mackenbach JP. The persistence of health inequalities in modern welfare states: the explanation of a paradox. Soc Sci Med 2012;75:761-9.

316. Rodriguez RA. Dialysis for undocumented immigrants in the United States. Adv Chronic Kidney Dis 2015;22:60-5.

317. Pavli A, Maltezou H. Health problems of newly arrived migrants and refugees in Europe. J Travel Med 2017;24.

318. Matesanz R, Marazuela R, Domínguez-Gil B, et al. The 40 donors per million population plan: an action plan for improvement of organ donation and transplantation in Spain. Transplant Proc 2009;41:3453-6.

319. Acevedo-Garcia D, Almeida J. Special issue introduction: place, migration and health. Soc Sci Med 2012;75:2055-9.

320. Terasaki G, Ahrenholz NC, Haider MZ. Care of adult refugees with chronic conditions. Med Clin North Am 2015;99:1039-58.

321. Van Biesen W, Vanholder R, Ernandez T, et al. Caring for migrants and refugees with end-stage kidney disease in Europe. Am J Kidney Dis 2018;71:701-9.
322. Raghavan R. Caring for Undocumented Immigrants With Kidney Disease. Am J Kidney Dis 2018;71:488-94.

323. Wild V, Dawson A. Migration: a core public health ethics issue. Public Health 2018;158:66-70.

324. Luyckx VA, Miljeteig I, Ejigu AM, et al. Ethical Challenges in the Provision of Dialysis in Resource-Constrained Environments. Semin Nephrol 2017;37:273-86.

325. Qazi HA, Chen H, Zhu M. Factors influencing dialysis withdrawal: a scoping review. BMC Nephrol 2018;19:96.

326. EdCL C, TPd C, Carvalho CC, et al. Associação entre bem-estar espiritual e autoestima em pessoas com insuficiência renal crônica em hemodiálise. Psicologia: Reflexão e Crítica 2015;28:737-43.

327. Cruz JP, Colet PC, Alquwez N, et al. Influence of religiosity and spiritual coping on health-related quality of life in Saudi haemodialysis patients. Hemodial Int 2017;21:125-32.

328. Saisunantararom W, Cheawchanwattana A, Kanjanabuch T, et al. Associations among spirituality, health-related quality of life, and depression in pre-dialysis chronic kidney disease patients: An exploratory analysis in thai buddhist patients. Religions 2015;6:1249-62.

329. Lucchetti G, Almeida LG, Granero AL. [Spirituality for dialysis patients: should the nephrologist address?]. J Bras Nefrol 2010;32:126-30.

330. Dwarswaard J, Bakker EJ, van Staa A, et al. Self-management support from the perspective of patients with a chronic condition: a thematic synthesis of qualitative studies. Health Expect 2016;19:194-208.

331. Morton RL, Tong A, Howard K, et al. The views of patients and carers in treatment decision making for chronic kidney disease: systematic review and thematic synthesis of qualitative studies. BMJ 2010;340:c112.

332. Shommu NS, Ahmed S, Rumana N, et al. What is the scope of improving immigrant and ethnic minority healthcare using community navigators: a systematic scoping review. Int J Equity Health 2016;15:6.

333. Boehmer KR, Shippee ND, Beebe TJ, et al. Pursuing minimally disruptive medicine: disruption from illness and health care-related demands is correlated with patient capacity. J Clin Epidemiol 2016;74:227-36.

334. Jha V, Garcia-Garcia G, Iseki K, et al. Chronic kidney disease: global dimension and perspectives. Lancet 2013;382:260-72.

335. Rosenzveig A, Kuspinar A, Daskalopoulou SS, et al. Toward patientcentered care: a systematic review of how to ask questions that matter to patients. Medicine 2014;93:e120.

336. Nugent RA, Fathima SF, Feigl AB, et al. The burden of chronic kidney disease on developing nations: a 21st century challenge in global health. Nephron Clin Pract 2011;118:c269-c277.

337. Garcia-Garcia G, Jha V. World Kidney Day Steering C. Chronic kidney disease in disadvantaged populations. Transplantation 2015;99:13-16.

338. Silva AS, Silveira RS, Fernandes GF, et al. [Perceptions and changes in the quality of life of patients submitted to hemodyalisis] Rev Bras Enferm 2011;64:839-44.

339. Gullick J, Monaro S, Stewart G. Compartmentalising time and space: a phenomenological interpretation of the temporal experience of commencing haemodialysis. J Clin Nurs 2017;26:3382-95

340. Kaba E, Bellou P, lordanou P, et al. Problems experienced by haemodialysis patients in Greece. Br J Nurs 2007;16:868-72. 